\title{
Motivation in sport: Bridging historical and contemporary theory through a qualitative approach
}

Daniel J. Leidl

West Virginia University

Follow this and additional works at: https://researchrepository.wvu.edu/etd

\section{Recommended Citation}

Leidl, Daniel J., "Motivation in sport: Bridging historical and contemporary theory through a qualitative approach" (2008). Graduate Theses, Dissertations, and Problem Reports. 2739.

https://researchrepository.wvu.edu/etd/2739

This Dissertation is protected by copyright and/or related rights. It has been brought to you by the The Research Repository @ WVU with permission from the rights-holder(s). You are free to use this Dissertation in any way that is permitted by the copyright and related rights legislation that applies to your use. For other uses you must obtain permission from the rights-holder(s) directly, unless additional rights are indicated by a Creative Commons license in the record and/ or on the work itself. This Dissertation has been accepted for inclusion in WVU Graduate Theses, Dissertations, and Problem Reports collection by an authorized administrator of The Research Repository @ WVU.

For more information, please contact researchrepository@mail.wvu.edu. 
Motivation in Sport:

Bridging Historical and Contemporary Theory

Through a Qualitative Approach

Daniel J. Leidl

Dissertation submitted to the

College of Physical Activity and Sport Sciences

at West Virginia University

in partial fulfillment of the requirements for the degree of

Doctor of Philosophy

in

Kinesiology with an emphasis in

Sport and Exercise Psychology

Edward Etzel, Ed.D., Chair

Samuel Zizzi, Ed.D.

Vanessa Shannon, Ph.D.

T.Anne Hawkins, Ph.D.

Jaci Webb-Dempsey, Ph.D.

Sport and Exercise Psychology Program

Morgantown, West Virginia

2008

Keywords: achievement, motivation, coaching 


\section{ABSTRACT \\ Motivation in Sport: \\ Bridging Historical and Contemporary Theory \\ Through a Qualitative Approach}

Daniel J. Leidl

From intrinsic and extrinsic motivation to attributions and goal orientation, theory and study related to motivation in sport abound. However, theorists such as Adler (Adler, 1998), Frankl (1984), and Maslow (Maslow, 1962) detail broader motivational frameworks that focus on a human impulse to derive meaning and purpose by extending beyond the self. While such theories take prominent positions within psychology, there applicability to sport has seemingly been overlooked. In an effort to explore more traditional motivational constructs in sport, a qualitative analysis of elite lacrosse coaches $(n=7)$ was conducted. Through semi-structured interviews, coaches shared their motivation to coach and how they motivate others. In these interviews coaches articulated a number of motivational constructs that extend beyond much of the contemporary theory. In analyzing these interviews, it is apparent that further work related to broader motivational constructs may be required to more wholly define motivation in sport. 
Table of Contents

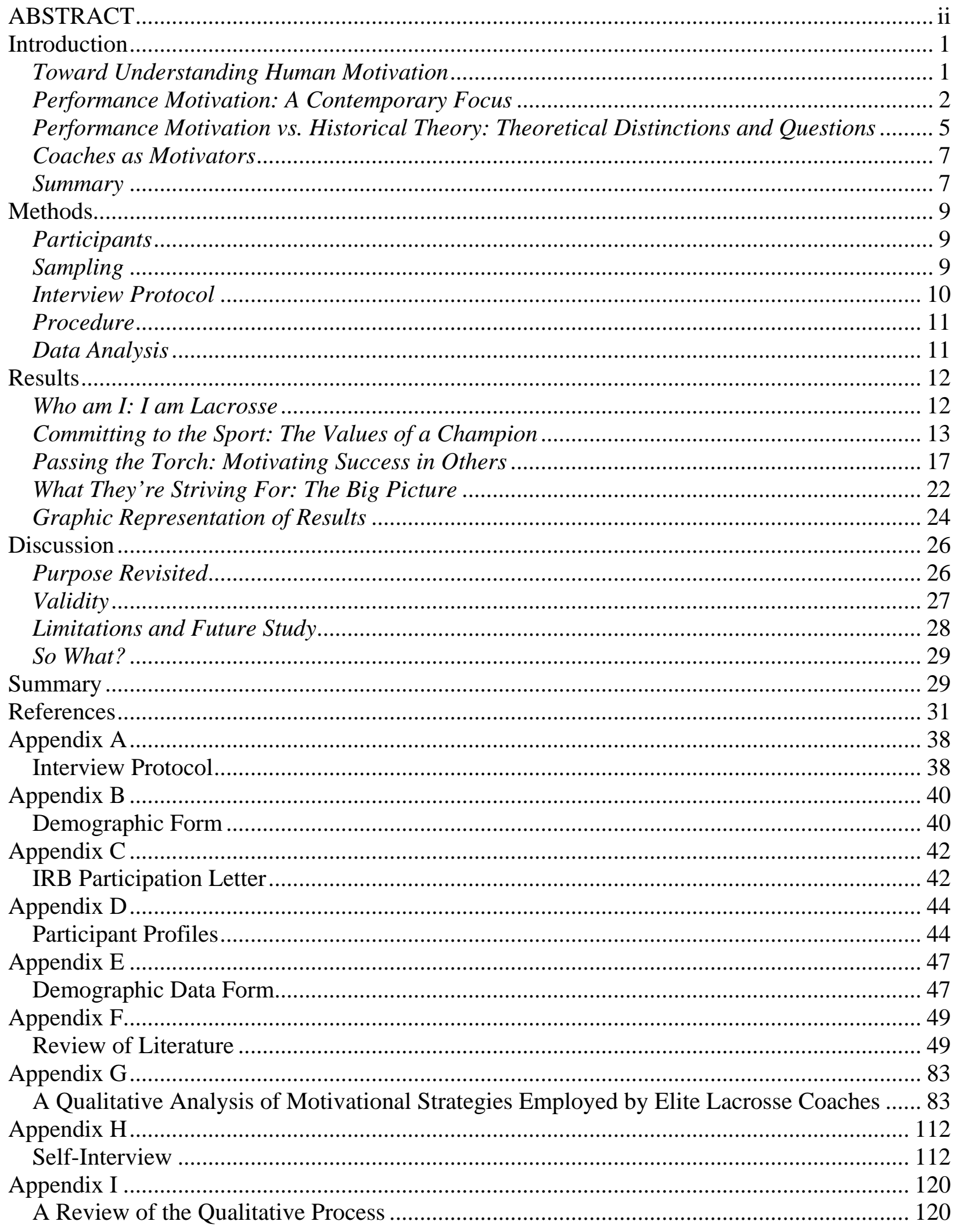




\section{Introduction}

“Each atom of that stone, each mineral flake of that night-filled mountain, in itself forms a world. The struggle itself toward the heights is enough to fill a man's heart. One must imagine Sisyphus happy.” (Camus, 1991, p. 123)

\section{Toward Understanding Human Motivation}

As Camus suggested, even the tragic Greek character Sisyphus finds contentment in expressing himself through his boulder pushing. In accordance with the Greek myth, Sisyphus may not have had a choice as to whether or not he would push that boulder up and down those mountains; but perhaps, Sisyphus’ boulder is more than a metaphor for modern man's struggle and a life less inspired. Perhaps that boulder, Sisyphus' efforts, and the presumption of contentment all serve as metaphors for a fundamental human impulse. Perhaps they serve as metaphors for the human effort to advance, the urge to assert oneself in the context of something greater than the individual, a base motivation to extend beyond the self.

For decades, the likes of Adler, Frankl, and Maslow have posited that people are motivated to express themselves through something beyond the self (Adler, 1998; Frankl, 1984, 1988; Maslow, 1962, 1970a, 1970b, 1971). Through such frameworks, the individual is seen as an advancing entity, compelled to assert him/herself in the context of something greater, something meaningful. As Griffith and Graham (2004) noted, “and so the human condition is the perpetual striving for superiority or overcoming” (p. 26).

Although this notion of human striving may be well documented by some of psychology’s preeminent theorists (e.g., Maslow, Frankl, and Adler), it is a vast and vexing perspective of motivation that may serve to overwhelm contemporary empirical researchers. In fact, in looking at the motivation rich environment of sport, little research has focused on this 
fundamental notion of motivation. Maslow (1970b) contended, "What a man can be, he must be” (p. 46). Similarly, Csikszentimihalyi (1990) suggested that "Each of us has a picture, however vague, of what we would like to accomplish before we die. How close we get to attaining this goal becomes the measure for the quality of our lives” (p. 9). However, contemporary research dedicated to sport and motivation has focused on less ambiguous and more explicit motivational issues. Specifically, much of the literature dedicated to understanding motivation in sport is related to achievement goals (Cain \& Dweck, 1995; Duda \& Nicholls, 1992; Grant \& Dweck, 2003), intrinsic and extrinsic motivation (Botterill, 2005; Eliot, 2005), and attribution theory (Biddle, Hanrahan, \& Sellars, 2001; Duda \& Treasure, 2001). Performance Motivation: A Contemporary Focus

Theories such as intrinsic and extrinsic motivation (Botterill, 2005; Eliot, 2005), attribution theory (Biddle et al., 2001; Duda \& Treasure, 2001), and achievement goals (Duda \& Hall, 2001; Duda \& Nicholls, 1992; Grant \& Dweck, 2003) are not only sound, they have also proven fertile ground for empirical research. However, they are also departures from the historical and universal perspectives mentioned above, as they present focused accounts of motivation in the context of performance.

Intrinsic and extrinsic motivation. Simply put, intrinsic motivation is associated with internal drives while extrinsic motivation is associated with motives that extend beyond the individual (Botterill, 2005; Duda \& Treasure, 2001; Eliot, 2005; Smith, 2001; Vallerand \& Rousseau, 2001). When examining motives in the context of sport, intrinsic motivation pertains to the expectation of enjoyment and satisfaction that an activity may illicit (Vallerand \& Perreault, 1999). In contrast, those who participate in an activity for social prestige, money, awards, recognition, etc. are extrinsically motivated (Vallerand \& Rousseau, 2001). 
Furthermore, according to this approach individuals are motivated to perform and/or engage in sport in response to a mix of external and internal drives (e.g., playing ball is fun; I get paid for playing).

Attribution theory. Similar to intrinsic and extrinsic motivation, attribution theory assumes that individual motivation is a product of several distinct mechanisms. Performance is viewed through the lens of three general attributes: locus of causality (internal - external), stability (unstable - stable), and locus of control (uncontrollable - controllable) (Biddle, et al., 2001; Singer \& Orbach, 1999). As per attribution theory, motivation is dependent on the performer's perspective of how these attributes influence achievement or failure, and the manner in which the three attributes are perceived will influence the individual's motivation to attempt the task in the future. For example, an individual who believes that s/he can consistently hit a golf ball and is generally in control of his/her swing will likely line up to hit that ball over and over. In comparison, one who does not feel in control and perceives success as a "fluke", sees failure as relatively stable, and does not feel a sense of control is unlikely to be motivated to continually whack at the ball (Biddle, et al., 2001; Singer \& Orbach, 1999).

Achievement goal theory. In contrast, according to achievement goal theory individuals are motivated by the goals they associate with performance (Duda \& Treasure, 2001; Grant \& Dweck, 2003; Harwood, 2005). The types of goals that individuals associate with achievement can be grouped into two main categories: performance/ego goals and task/mastery goals (Duda \& Hall, 2001; Grant \& Dweck, 2003). The degree to which an individual adopts performance/ego goals or task/mastery goals ultimately influences the individual's motivation. Those who adopt task/mastery goals value the effort that leads to success because they are interested in improving, learning, and developing skills necessary for future achievements 
(Duda \& Nicholls, 1992; Dweck, 1986; Elliott \& Dweck, 1988). Individuals who are performance/ego goal oriented focus on end results, innate ability, and engaging in activities in an effort to prove their worth and avoid criticism (Cain \& Dweck, 1995; Duda \& Nicholls, 1992; Nicholls, Patashnick, \& Nolen, 1985). Individuals who associate achievement with task/mastery goals are generally considered to be more likely to persist in the face of adversity, as they see failures as temporary setbacks (Ames \& Archer, 1988; Duda, Chi, Newton, Walling, \& Catley, 1995). Conversely, those who associate achievement with ego/performance goals may shy away from challenges that could expose a lack of ability or expertise, feel helpless in overcoming setbacks, and consider ability to be influenced by genetics and fate rather than hard work and diligence (Duda et al., 1995; Smiley \& Dweck 1994).

Mindsets. Dweck seems to have synthesized the aforementioned perspectives into one overarching concept (Dweck, 2006). Research by Dweck suggests that goal orientation influences individual attributes (e.g., causality, stability, control), which may prompt individual feelings of helplessness or motivation (Dweck, 1986; Dweck, 1992; Elliott \& Dweck, 1988; Hong, Dweck, Chiu, Lin \& Wan, 1999; Smiley \& Dweck, 1994). In her work with Hong et al. (1999), it was suggested that, "implicit theories set up frameworks within which attributions occur” (p. 597). In other words, an individual’s attributions are influenced by the goal orientation s/he adopts. For example, if one has adopted a task/mastery orientation, s/he may attribute failure to unstable causes that can be overcome and controlled with hard work and needed preparation. To this end, individuals with task/mastery goal orientations and corresponding attributes maintain motivation due to their enthusiasm for the process of preparing for achievement. Of note, this perspective seems consistent with intrinsic motivation. 
Most recently, Dweck (2006) expanded the notion of goal orientation, suggesting that larger frameworks, namely “mindsets”, are primarily responsible for the goal orientations people adopt. These mindsets are thought to influence individual goal orientations, which can affect the individual's motivational attributes (e.g., causality, stability, control) and intrinsic motivation. Dweck (2006) proposed two distinct mindsets: fixed and growth, defining them in broader terms than the existing task/mastery and ego/performance goal orientations. An individual with a fixed mindset may contend that ability and skill are innate and limited by genetics and fate, while someone with a growth mindset believes that ability grows with effort and determination (Dweck, 2006).

In summary, an individual's mindset influences goal orientation, goal orientation influences attributions, and they combine to influence motivation. Intrinsic motivation is achieved when individuals enjoy what they do, while extrinsic motivators influence the motivational climate in which individuals perform. Although Dweck's work is consistent with the previously mentioned theories it is unique in its totality and scope, and worth mentioning in this brief review of the more prominent contemporary theories that relate to motivation in sport. Performance Motivation vs. Historical Theory: Theoretical Distinctions and Questions

While more contemporary theories pertaining to motivation in sport may do well to articulate and identify performance motives related to achievement goals (Duda \& Hall, 2001; Grant \& Dweck, 2003; Nicholls et al., 1985), intrinsic and extrinsic motivation (Botterill, 2005; Eliot, 2005; Vallerand \& Rousseau, 2001), and attributions (Duda \& Treasure, 2001; Eliot, 2005), significant questions remain. While these theories have served to influence and enhance the field of sport psychology, the motivational issues that they address are arguably singular and/or narrow in scope. The central motivational concern of these theories is aptly performance 
(e.g., the motivation to engage in a specific task with a specific level of effort and/or enthusiasm), as they offer insight into the motives behind task specific behaviors and how to foster adaptive perspectives. However, the performance motivation literature provides modest insight into what motivates an individual to engage in a behavior in the first place. Why does a person play soccer or the piano? While an intrinsically motivated response could simply be, "Because it is fun" or "I like it", the process is seemingly more complex as a variety of additional variables should be considered (e.g., why play on a team or for an audience, why not focus on getting a job as opposed to an athletic scholarship, or simply record songs in your house if composing is what you enjoy).

In assessing the theoretical conceptions of more traditional theorists such as Adler (1998; Ansbacher \& Ansbacher, 1964; Manaster \& Corsini, 1982), Frankl (1984, 1988), and Maslow (1962, 1970a, 1970b, 1971), additional motivational forces may serve to inspire athletic participation, team play, and rigorous physical efforts. Such theories suggest that individuals engaged in sport may be doing so for more complex purposes that can not be exclusively explained by contemporary sport psychology theory. In accordance with such theories, people may engage in sport for complex, psychologically inspired reasons: to find meaning and purpose in life, positively contribute to an organized social milieu, advance and actualize the self, and/or express the essence of oneself through an accessible and inspiring medium.

While there appears to be a gap in the literature that separates contemporary sport psychology and more traditional theory related to motivation, confounding the dearth of research related to the motivational concepts put forth by more traditional theorists is the fact that such concepts seem to be alive and present within the world of sport. In his essay, "Sport as Escape", Segrave (2000) suggested that one "of sport's seductive charms: it can offer what life often 
cannot, a clear sense of purpose and meaning” (p. 71). Reflecting on his days as a gifted runner, Joseph Campbell (2003) stated, “That's the mysticism of athletics. . .and the experience is the experience of a truth.” (p. 41). Similarly, books by and about coaching such as Sacred Hoops (Jackson \& Delehanty, 1995), Season of Life (Marx, 2003), Wooden (Wooden \& Jamison, 1997), and The Education of A Coach (Halberstam, 2005) abound with metaphors and anecdotes that relate to themes of transcendence, meaning, socially significant pursuits, teamwork, and self actualization. Consistent with the sentiments of Maslow, Frankl, and Adler, such quotes and larger works suggest that there may be good reasons to further explore the connections between sport and more traditional motivational constructs.

\section{Coaches as Motivators}

In exploring such constructs, it would seem apt to begin by speaking directly with coaches. Coaches drive, teach, and motivate their teams in the pursuit of success. As Hardy, Burke, and Crace (2005) suggest, "The essence of coaching comes down to teaching and motivating” (p. 191). In their roles as leaders, coaches plan practices, maintain pre- and postcompetition routines, focus on having fun when teaching, advance their knowledge of their sport, review film, and much more in the name of advancing the athletes they lead (Bloom, DurandBush, \& Salmela, 1997; Bloom \& Salmela, 2000). Coaches are in a unique role to motivate others. Further exploring their motivational thinking and methods may provide insight into general motivational practices. As the leaders of the sporting world, coaches are appropriate subjects for further analysis into motivational strategies related to the individual's pursuit for excellence, meaning, social advancement, and/or self-actualization through sport.

\section{Summary}


From posters and speeches to the overall team climate, coaches have the ability to influence their athletes in profound and meaningful ways (Adegbesan, 2001; Ames \& Archer, 1988; Cain \& Dweck, 1995; Vargas-Tonsing, 2004). Regarding his experiences playing and learning from John Wooden, Swen Nater stated, "It was his life that changed my life.” (Nater \& Gallimore, 2006). This is a seemingly profound statement for a player to make about a coach, but insightful with regard to how much impact a coach can have. However, it would seem that there is much to be learned with regard to how coaches motivate, and why sport offers opportunities for coaches to make such profound impacts.

While insight and understanding is being obtained regarding how intrinsic and extrinsic motivators, achievement goals, and attributions can serve to motivate, little seems to be known about how and why athletics can motivate the types of life changing efforts that Nater references (Nater \& Gallimore, 2006). More traditional theories offer insight into the possibility of underlying human urges that motivate action and effort, while also addressing basic human motives to advance within the context of a larger medium, actualize the self, and be a productive part of a group. By harkening back to historical theory, new doors may be opened with regard to the motivational constructs that exist in sport, and how master coaches can motivate players to pursue athletic achievements. Therefore, the purpose of this study was to explore the existence of more traditional motivational theory within sport, and how it is exercised by coaches. 


\section{Methods}

\section{Participants}

The participants in this study included active male $(n=4)$ and female $(n=3)$ coaches whose teams have won a National Championship in the sport of lacrosse. All active Division I and Division III head lacrosse coaches who have won an NCAA National Championship at the level they currently coach at were eligible for participation $(n=15)$. The final participant pool $(n=7)$ consisted of three Division III coaches $(n=3)$ and four Division I Coaches $(n=4)$ (Detailed descriptions of each coach can be found in Appendix D). As a group, the coaches represent 151 years of coaching, and average 21 years experience. All of the participants have Bachelor's Degrees, two have Master’s Degrees, and all played lacrosse at various levels (Detailed demographic information can be found in Appendix E).

\section{Sampling}

Lacrosse is the fastest growing game at the collegiate and high school levels in the United States (US Lacrosse, 2006), and the oldest sport in North America (Vennum, n.d.). Nearly 150 men's and women's Division I lacrosse teams compete for 32 spots in the men's and women’s NCAA tournaments (LaxPower, 2008a, 2008b, 2008c, 2008d). Even more competitive, more than 320 men’s and women’s programs compete for less than 50 slots in the Division III tournaments (LaxPower, 2008e, 2008f, 2008g, 2008h). Among all active Division I men’s and women’s coaches only ten have led their teams to a national title, four active Division III women’s coaches have won NCAA championships, and only one active Division III men’s coach has won a National Championship with the school he remains coaching at (NCAA, 2007, 2008). 
Extreme case, criterion, and purposive sampling were employed in this study (Patton, 2002). Extreme case sampling relates to the rare levels of success the participants achieved (i.e., winning an NCAA Championship). Criterion sampling pertains to the manner in which the sample was chosen; it specifically relates to the fact that participants were limited to active coaches who have won National Championships. Finally, purposive sampling refers to the intentional focus on the population identified through the criteria (i.e., lacrosse coaches), and was used due to the primary investigator's experiences with the world of lacrosse and anticipation that the designated participant pool would yield a rich data set.

\section{Interview Protocol}

The interview protocol was assessed and revised over a two year period. The initial pilot protocol was reviewed and critiqued by a licensed psychologist and faculty member who has an extensive background in sport psychology and social psychology. Additionally, an elite Division III lacrosse coach volunteered to practice the interview and provide feedback on quality of the questions. A preliminary script was crafted and served as the basis for six interviews that comprised a pilot research program (Leidl \& Frontiera, 2007; Leidl, Frontiera, \& Siestreem, 2008). The initial protocol contained five questions: two focused on team culture and three related to motivation.

Subsequent to the pilot interviews and further investigation into motivational theory, a revised protocol was developed (Appendix A). The protocol is comprised of nine questions that relate to motivational forces that guide coaches, motivational constructs inherent in the sport of lacrosse (i.e., tradition, social network, etc.), and motivational strategies employed by coaches. Additionally, the protocol has been critiqued and edited with the assistance of an expert in qualitative methods. 


\section{Procedure}

Coaches eligible for participation in the study were contacted by phone soon after the end of the 2008 season. Coaches were asked to meet at their offices or a convenient location (e.g., Instructional Camps) when their schedule could accommodate the interview. All coaches who were interested in participating met for a face to face interview that was audio-recorded. As per IRB protocol, all coaches received a copy of a letter stating the purpose of the research and intentions for involving them (Appendix C). Semi-structured interviews were conducted with all participants so as to foster expressive and communicative climates in which participants were encouraged to share experiences and beliefs that could extend beyond the direct line of questioning (Bogdan \& Biklen, 1992; Patton, 2002). Interviews lasted between one and two hours, and all coaches suggested that the primary investigator should feel free to follow up for any additional information/clarification.

\section{Data Analysis}

As described by Strauss and Corbin (1990), “One does not begin with a theory, then prove it. Rather, one begins with an area of study and what is relevant to that area is allowed to emerge” (p. 23). In analyzing the data, the words of the subjects were reviewed and categorized so as to organically capture emergent themes. According to Bogden and Bilken (1992)

“'Meaning' is of essential concern to the qualitative approach”. Consequently, the participants sentiments were grouped in accordance to their meanings. All interviews were transcribed verbatim, and a modified version of interpretive analysis was employed: the data was reviewed with the expectation of identifying emergent themes, themes relating to relevant literature and current research were noted, impressions of the data were recorded and categorized, codes and categories were developed and refined in accordance with discussion between two additional 
researchers, and excerpts were identified to exemplify the final codes and categories (Hatch, 2002). Additionally, three methods of triangulation were then used to assess and interpret the data so as to strengthen the integrity of the findings and the general reliability of the final report: data triangulation, investigator triangulation, and theory triangulation (Patton, 2002, p. 247).

To enhance objectivity and ensure investigator triangulation, the principal investigator invited the feedback of two additional researchers (i.e., graduate students with experience in qualitative methods). The three researchers independently reviewed and analyzed the data, and after that met to develop a consensus regarding codes, categories, and themes. Data was triangulated through contrasting and comparing the responses of the various participants, and was also subject to theory triangulation. Historical and more contemporary motivational theory were assessed in relation to the data, affirming or denying a true gap in the literature devoted to motivation in sport.

\section{Results}

The results have been arranged to reflect themes that emerged from the data and are labeled accordingly. So as to not obscure the meaning of individual responses, while respecting the value of the participant's thoughts, explanations and interpretations were kept to a minimum. Larger themes have been broken down into more digestible categories, and headings will serve to indicate when this is taking place. Finally, in an effort to more comprehensively bracket out any biases, brief profiles of each coach can be found in Appendix D.

\section{Who am I: I am Lacrosse}

All seven of the participants expressed an intimate relationship with the sport of lacrosse, suggesting an intense level of identification where life and lacrosse were somewhat blurred. 
Lacrosse is a passion that they identify with and fully invest in. To these coaches lacrosse is a part of who they are. As stated by Coach 6:

I have never been somebody who’s tried to separate his job and his life. I take work home. I take my work home, I'm happy to do that. My wife understands . . . I don't say anything differently to my players that I'm going to say to my son. When you do it like that then you don't have to remember which goes where. In this sense, these coaches have melded their passion for lacrosse with their lives. They assert themselves through the game and identify with what the game gives back. As Coach 4 said, "I mean, this is what I do, lacrosse is my life, I love it.”

Each coach expressed a dedication to lacrosse and the players they serve. In many ways, their individual investment to the sport serves as the basis for further understanding how they motivate others. They are wholly committed to the sport and the athletes they serve, and are willing to do what it takes to find success while positively influencing others. They have found a level of comfort and attraction in committing to lacrosse as a medium, and believe in the value of their commitment. In the words of Coach 3:

Lacrosse is kind of like the old worn in shirt, you know, that just feels really cozy, and you don't want to give it away. It's never going to Salvation Army. It's like it just fits, and it works, and it comes very naturally to me.

\section{Committing to the Sport: The Values of a Champion}

When working to motivate their individual players and teams, all of the coaches expressed a commitment to a range of values that seemed to serve as a foundation for all other motivational strategies and activities. These coaches dedicated themselves to a series of ideals that they perceived to be instrumental for modeling success and motivating others to strive for 
achievements. They embodied these values and in turn worked to instill them in the players they worked with. These values, as well as the number of participants who spoke about them during the interview include: empowerment (6), camaraderie (6), hard work (7), growth (7), committing to excellence (6), a generative responsibility (7), and fun (6).

Empowerment. Six of the coaches explicitly expressed a commitment to empowering their players. As Coach 5 stated, “. . . we asked them for their help. I mean they were as much a part of it as we were.” The coaches generally believed that providing players with a voice proved inherently motivational, and was a value that they wanted to extend throughout their programs. By giving the players an opportunity to contribute to their experiences and ultimately share in the molding of the programs they played for, the coaches believed that they could maximize player buy-in, motivation, and effort. As articulated by Coach 3, "I had a big shift probably five or six years into my time at [School Name] where I realized that I had to have them own their own goals, and that I couldn’t instill my own goals on them.”

Camaraderie. Working together proved to be a significant value that was discussed by six of the participants. The idea that players can play for each other, represent a dynamic group, and work together to perform great achievements is a seemingly powerful value that the coaches worked to develop and explore with their teams. Coach 1 spoke of this dynamic, reflecting how she relates her belief and commitment to camaraderie to her players, stating, "you're going to have very few opportunities in your life where you are able to be a part of a group that becomes something really bigger than you, and it's not just about yourself, it's about us as a group, and you're responsible for one another. . .“

Coach 6 shared a similar sentiment when he spoke of how he has worked to further emphasize the importance of camaraderie within the team dynamic, and how it can be used to 
motivate his players. He said, "I've been a little bit struck in the last few years with this whole thing of, you know, convincing guys that it's worth it. Now what is it? What is it exactly? It is this sense of doing something together.” In stating the value of working as a group in these terms, these coaches are advancing a conception of camaraderie that would seem to extend beyond the field of play. In this regard, Coach 4's view of togetherness is poignant and straight forward:

I love coaching here because if I walk down a dark alley in New York City from [School Name], and I know the [School Name] guys are behind me, I don't have to turn around and look. A lot of other schools you have to look because you're worried who’s walking down that alley with you and going to battle. . .you guys are all brothers who all love each other. . .when we go to do something we're going to do it all together.

Hard work. Coach 5, in particular, spoke passionately about committing to hard work, stating, “. . . I sacrifice things in my personal life. Thankfully I have a really understanding wife. I struggle to find balance.” While the other coaches may have used different terms, there was a shared sentiment among all of them that continual effort is a key value and essential ingredient for success. As with the other values, the promotion of hard work is modeled and advanced by the coaches. Coach 2 articulated this value in her own way, stating that “. . we lose that one game and we all come together as a staff and we reevaluate all of our drills, all of our messages, who’s doing well, what do we need to do.”

Growth. Each coach expressed a commitment to individual growth. Coach 3 stated, “I've learned to seek out people that know more than me. . . I think there're people out there that you have so much to learn from.” The participants suggested that growth is an essential 
component of who they are, and instrumental in fostering a motivational atmosphere where players can also continually develop. Similarly, Coach 7 spoke of his growth throughout his tenure as a coach:

I consider myself a much better coach now then I was when I was thirty and at [School Name], when I won three National Championships. I'm a much better coach now, much better coach. I don't even think it’s close, and it's because I have a better perspective on things.

Committing to excellence. Make no mistake, each coach interviewed wants to win, get the most out of his/her teams, and see his/her athletes do their best. While this value was expressed in different ways, six of the coaches spoke of committing to a high standard of excellence that they were not willing to waiver on. Perhaps most succinctly captured by Coach 1, each coach wanted to win, but wins were more of a byproduct, resulting from a commitment to excellence:

I always say at the beginning of the season, my goal for you guys isn't to win a National Championship, we're taking that off the table right now. If we do, yippy, no one loves to win more than me, but my goal is, really, that you guys perform at a high, high, high level this season.

A generative responsibility. Beyond the more performance-based values that have been expressed thus far, all seven of the participants articulated a drive to give back, a motivation to continue success through his/her program, a compulsion to be a mentor for younger players. As Coach 3 said, "I feel like I have something to give to young people, and I feel like lacrosse is a medium to do that." In this sense, each coach harbored a generative responsibility, and saw themselves as gatekeepers to their teams as well as the game itself. They modeled this value 
through their own commitment, suggesting a philanthropic approach to coaching. Coach 7 succinctly stated, “. . . part of my mission as a teacher of the game is to pass down the heritage.”

Fun. "And that's the other thing, it's got to be fun. I really believe this is a game, it's a game and games are played to have fun.” As per Coach 7's quote, there was a consensus that lacrosse is meant to be enjoyable, and players are generally most motivated when they are enjoying themselves. This was a value that the participants seemed committed to, as six of them mentioned it specifically. The participants saw a value in promoting a sense of fun in their programs, believing that players were most motivated when they enjoyed what they were doing. Perhaps best articulated by Coach 1: “I can’t wait until 3:30 when I know I'm going to walk out the door and spend my time with you, even if it’s snowing or raining or cold. This is the best part of my day and I hope it's the best part of your day too.” Passing the Torch: Motivating Success in Others

While the participants shared a clear set of values that serve to maintain a general motivational climate, they also described motivational efforts that intentionally articulated and highlighted those values. In this sense, the participants worked to actualize their values, and were committed to putting belief into practice. The coaches shared a number of practices that they use to maintain motivation among their players while challenging them to continually strive to attain the values previously described. The number of participants who spoke about each individual effort is in parentheses, and the efforts include: off-field efforts (7), stories: capturing the history (4), reminding them: reinforcing a mindset (6), accountability (6), the culture of edging(5), competition (7), and sustaining success (7).

Off-field efforts. Whereas motivational efforts that took place off the field were varied, they related to talks, exercises, meetings, etc. that articulated the values of the team while also 
serving to amplify or maintain motivation among the players. Coach 4 spoke of carrying a stuffed seagull (the school's mascot) on the bus as they neared the playoffs. The seagull had been with the team since 1994, had "been to a lot of Championships", and served to remind young players of the past while keeping the Championship run fun for the veterans. In all instances, these coaches engaged in activities that reminded players that they cared, while also motivating players to play hard, trust the coaching staff, focus on preparation, etc. To follow is an example given by Coach 7 that may best serve to capture the sentiment of this category: ... we were at [School Name], and we had a good team but we were struggling a little bit, and we were playing Army. I went out and I bought a mirror, and on the bottom of the mirror, I cut out the numerical roster of our team, and I taped it on the bottom of the mirror. And taped the mirror to the board where the guys, normally when the guys walk in our locker room the day of a game, there's a message on the board, alright. So instead of having a message it had, here is the key to beating Army, and it was covered with a towel. So a guy walked in, it said here's the key to beating Army, he flipped up the towel and he saw himself, yet everybody’s name was on that mirror. So, yeah, I got to step up, but all these other guys are with me.

Stories: Capturing the history. Although not as overt as other sub-themes, stories seemed to serve as inter-team motivators, capturing the history and legacy of the program while inspiring future action. Four coaches spoke specifically of how stories were used to inspire and motivate players. Through stories coaches and athletes are able to articulate team values with concrete examples of players and instances. Coach 4 captured this sub-theme eloquently and directly when he spoke of stories and how he regularly shares them with his players: 
I would say it’s everyday, but usually every other day or something I will bring up a story or a person. I use the [Player's Name] story a lot. [Player's Name], I don't know if you know who [Player's Name] was, he's the all time leading scorer in the history of college lacrosse. . .if that was [Player's Name], he had those three shots, the ball would have been in the back of the net because, you know what, he wanted at the end of the day, he wanted to be 7 (goals) and 4 (assists) instead of 3 (goals) and 2 (assists). Cause he wasn’t going to let any opportunity get away, and he didn’t care if the dog was down, he was going to step on him.

Reminding them: Reinforcing a mindset. Coach 6 said, “... along the way you’re saying all these sacrifices fellas are going to be worth it”, and others echoed the same sentiment. Six participants specifically spoke of a need to remind the players of what they are working for, while also reinforcing the values of the program. Coach 5 stated, “... we do talk a lot about earning respect, and that you don't get respect just because you're [School Name]. You get it because you've earned it.” In this sense, actively reinforcing the program's values reminds the players of what they are there for while also motivating them to continue striving forward. As Coach 1 said:

... we're going to do this drill, and you can either go hard or you can go really hard, and you might want to think about sometimes how you get when you're in, how you act or feel when you're in another uncomfortable position in your life. Do you go kind of hard, or do you go all out? So sometimes I'll say that smack in the middle of practice. 
Accountability. In accordance with six of the participants' responses, accountability serves as a significant tool in the motivator's toolbox. Coach 2 spoke of a willingness to remove players from the team if they were unwilling to conform to team rules and expectations. Similarly, Coach 4 described his willingness to “call guys out” if they're not working hard enough or playing to their potential. For these coaches there are expectations and boundaries and if you don't meet one and/or cross the other, there are definitive consequences. Coach 5 described his philosophy in some detail:

...we do motivate a little bit out of fear here in that there are consequences for things for our guys. So if you don’t perform, you're not playing. If you don't do the little things, you're not playing. If you don't go to school, we're going to take it out on the whole team. So for instance, if a guy doesn't go to school and we catch him, then we run the whole team.

The culture of Edging. Coach 5 shared a sentiment that his teams have come to adopt: "no one wins a National Title in the fall, but the teams that coast through the off-season are defeated before the real games even start.” Five of the participants shared a belief that Championship teams may work harder than their competitors. Coach 3 said, "The culture of our program is we're in the weight room three times a week in the fall, or we're having fall ball twice a week. .." Similarly, Coach 1 said, "I’m expecting that our players are going to do all the little things. . " As with the case of Coach 4, his players have not only embraced the concept of doing extra work, they have created their own word for it:

Yeah, well we have this thing, we call it the Edge ... and the Edge stuff is stuff that's done outside of three to five. And I tell our kids every day ... don't kid yourself that you're working harder than those guys are between three and five. 
They're busting their ass for two hours, two and half hours, and so if we want to be better, we've got to do some of those things outside of three to five that's going to separate us from them. And whether that's extra wall ball before and after practice, whether it's extra shooting, whether it's extra lifting during the day, we're always talking about Edge workouts. Did you Edge today?

Competition. Fostering a sense of competition is essential to succeeding in a competitive arena, and all of the participants were diligent in preparing their teams for the competitive challenges they would see on the field. Whether promoting a sense of competition in practice with drills and games, or devising off-field competitions, the coaches infused competition into unexpected facets of their program. Coach 5 pitted each class (i.e., sophomores, juniors, etc.) against each other in a battle for the best grades. Coach 6 spoke of competitions that they scored and kept track of throughout the off-season, stating “... we met twice a week in the off-season, and did something competitive by team, whether it was ultimate Frisbee, or basketball, or touchfootball, or soccer, or weight lifting, or a long run, and uhh, and we kept standings”. Coach 3 also spoke of the power of competition to motivate her players, but highlighted the competition of other teams and the increasing parity in women’s lacrosse as a motivating force: “. . .the parity has really made us stay on our toes and just kind of stay focused and keep working”. In all of these examples, a sense of competition is fostered and actively promoted so as to heighten the motivation to compete come game time.

Sustaining success. Lastly, all of the participants spoke of the motivational power of sustaining success. In this sense, these coaches work with players who know what they are capable of, and seem to be motivated to do it. As Coach 6 stated, “Our program is at a level where we start out every September thinking that we have a chance to be playing on the last 
day.” The idea that a National Championship is within their grasp is inherently motivating to the athletes these coaches work with. Coach 4 said:

We've been fortunate for the last six years, being in the Championship game.

Once you've been to that weekend, there's nothing in life other than the day you get married and the day your first son's born that's any better than that weekend. And so, you're motivated to go back.

On the other hand, Coach 5 noted that the motivation to sustain success is not always inherent, and players may need to be reminded of the legacy that they are expected to maintain.

I said, you're not going to be remembered for the two Championships you were part of. You're going to be remembered, senior class, which is tremendously talented, for not making the playoffs. That's going to be your Johns Hopkins legacy. And when you leave here, and you come back, that's what you're going to be remembered for. I said, and that's what you're going to remember. Is that what you want to be remembered for? And that's motivating. Fear, fear of being responsible for that, and it worked, it worked.

What They're Striving For: The Big Picture

While the participants spoke of a strong desire to succeed on the field, they also spoke of a commitment to a 'bigger picture'. In this sense, all seven coaches expressed a commitment to pushing their players toward a level of personal development and growth that transcends lacrosse. They use lacrosse as a medium to impart larger life lessons, display the power of cooperative efforts, instill a vigorous work ethic, and inspire young players to develop and grow. 
Through this theme, the participants expressed a motive that brings us full circle. These coaches identify with being a coach, adopting and imparting values that they associate with success. They motivate their players to take on the values they hold dear through a number of exercises and techniques, and assume that on-field success will result when those values are achieved. In the end, those values not only bring about wins and rings, but they also mold the players into diligent and conscientious people who continue to strive for success in everything they do. It is this conception of motivating life change that may very well reenergize and motivate the coach.

Each coach interviewed had a profound take on what they can offer their players, and how it relates to something far greater than lacrosse. As per Coach 1, "I'm helping them have some 'Aha!’ moments in their life. And, I use lacrosse a lot as sort of a metaphor for life.” Similarly, Coach 6 stated, "You build something that has a sound base so that even if you lose before you're ready you still feel like we've accomplished something, we've at least moved in a common direction, and we have learned some things that are going to benefit us after this is all over." These coaches are committed to using lacrosse as a means of instilling larger life lessons and fostering impactful experiences. Perhaps best stated by Coach 7:

I'm a big big-picture guy. And I've been around for a long time, and now, I'm at that age where I have seen it all and so I can appreciate the big-picture. Versus, I think, some younger coaches, like I was when I was thirty years old. Boy, I had blinders on. It was all about, hey, x’s and o's, and getting out there and winning, and nah, nah, nah, nah, nah. Now to me it's, we focus more on the big-picture. And if our kids understand the big-picture, then they will understand how 
fortunate we all are to have the opportunities that we have to go to school, get an education and play this great game.

\section{Graphic Representation of Results}

In assessing the results, the following graphic representation is intended to further articulate the dynamic nature of the motivational process that emerged from the coach interviews. These coaches identify with the sport of lacrosse as coaches and harbingers of the game. In committing to coach lacrosse to the best of their ability, they have also committed to striving to exemplify a distinct value set. For the participants, success is contingent on adopting specific values, and they spend a tremendous amount of effort instilling these values in their teams. Through a variety of exercises and efforts, these coaches are actively working to promote growth and value-laden commitment in their players. In doing this, these coaches have articulated a dedication to something far bigger than lacrosse. The participants are striving to promote growth in their players that will extend beyond the playing field. In coming full circle, their dedication to the big picture reinforces their identification with lacrosse. In essence, lacrosse is a medium through which these coaches inspire young athletes to become better people, which in turn inspires the coaches to keep coaching. 
Figure 1. Graphic representation of results.

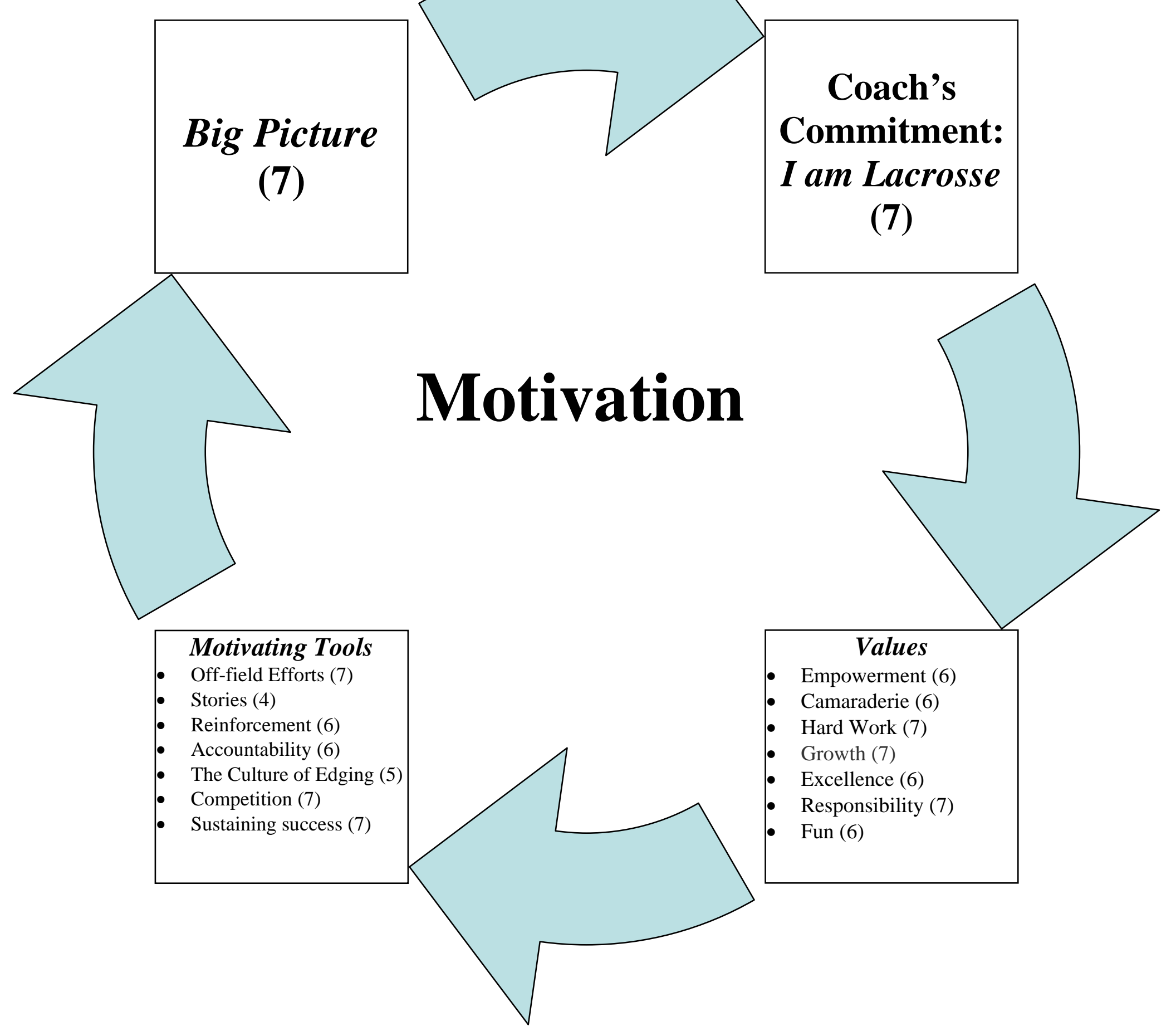




\section{Discussion}

\section{Purpose Revisited}

The purpose of this study was to explore the existence of historical motivational theory within the sport of lacrosse, and how it is exercised by elite collegiate lacrosse coaches. What is perhaps most striking about the findings of this research is how similarly the participants spoke of their motivational perspectives and philosophies. They all spoke of using lacrosse as an instrument for promoting excellence and personal development in others. Additionally, they did so in an almost scripted manner: embracing their individual passion for lacrosse, adopting a value laden perspective of how to succeed, actively motivating their athletes to pursue such values, and finally committing all efforts toward a big picture ideal that extends far beyond the playing field.

Given these findings, motivation in the sport of lacrosse and sport in general may extend beyond the more contemporary research related to intrinsic motivation, attribution theory, and achievement goal theory. The participants actively engage in motivational tactics and behaviors that may compliment contemporary theory, but there seems to be more to the story. Specifically, broader historical concepts of motivating others through deeper meanings, the pursuit of self actualization, and a commitment to prosperous social networks also abound (Adler, 1998; Ansbacher \& Ansbacher, 1964; Manaster \& Corsini, 1982; Frankl, 1984, 1988; Maslow, 1962, 1970a, 1970b, 1971). For example, the concept of the big picture, a responsibility to perpetuate a specific value set, and actively motivating others with stories and socially shared goals of continued success are all motivational ploys that aptly fit in the more historic theoretical camps. 
In more specific terms, Adler (1998) stated, "life is the attainment of a goal or ideal form, and it is the striving for superiority that sets it in motion” (p. 39). In this sense, these coaches seemingly embody such a perspective, embracing values such as hard work, committing to excellence, and growth while working to instill such values in their athletes through the promotion of competition, accountability, and sustaining success. The participants use lacrosse as a means to attain goals and work for success both on and off the field by striving to win championships and focusing on a big picture. Similarly, Frankl (1984) argued that “Man’s search for meaning is the primary motivation in his life. . " (p. 121), and that "there are three main avenues on which one arrives at meaning in life.” (p. 170). Those avenues include work, relationships, and individual growth (Frankl, 1984), and are actively embraced by the participants. The motivational practices of the interviewed coaches are rooted in a historical context, as they are motivating their athletes to value empowerment, camaraderie, hard work, and growth while actively motivating them through a culture of edging, stories of previous players and achievements, and off-field efforts that strengthen bonds and awareness.

As articulated through their values, their motivational efforts, and their commitment to a big picture, as well as lacrosse, the interviewees are continually putting more historical theory into practice. They are motivating athletes toward pursuing individual and socially enriched meaning, while also preaching the importance of striving for excellence and self improvement. To this end the purpose of the study has been richly fulfilled, as more historical motivational theory is seemingly present and full of life in the sporting context analyzed. Validity

Internal validity was assured through data triangulation, theory triangulation, and investigator triangulation (Merriam, 2002). By interviewing seven different subjects, assessing 
various contemporary and historical theoretical perspectives, and drawing on the expertise of two additional researchers to review the data, efforts were made to strengthen the study's internal validity. Additionally, as noted earlier, the questions that comprised the protocol were crafted over the course of two years with input from experts as well as other lacrosse coaches.

In the tradition of qualitative research, external validity is contingent upon the reader's ability to relate to the text (Merriam, 2002). While the findings from this study are consistent with pilot research that focused on similar participants and research questions (Leidl et al., 2008), the true test for external validity will be if other's relate to the concepts and excerpts included herein. With that said, clearly it remains inconclusive as to what extent the findings of this study can be generalized to other coaches and sport settings.

\section{Limitations and Future Study}

As with all research, this study is not without its limitations. First, the primary investigator has a rich background in the world of lacrosse. In this sense, there is clearly strength in being knowledgeable about the participants and topics one is investigating. However, perhaps the objectivity of the study could have been enhanced if someone less entrenched in the world of lacrosse co-conducted or led the interviews. With regard to the sample studied, in focusing on such an accomplished set of participants in lacrosse, one can only wonder if less-accomplished coaches as well as coaches from other sports would have provided similar perspectives on the topics of inquiry. Additionally, it may have been useful to have interviewed the assistants and players of the coaches who comprised the sample so as to corroborate their views and responses. Finally, it may not only be beneficial to assess additional groups of participants, but it may also be helpful to employ additional measures. It could be that quantitative measures, questionnaires, or even a modified interview protocol could yield intriguing and valuable results. 


\section{So What?}

It would seem that historical motivational concepts exist in the efforts of contemporary elite lacrosse coaches. However, more research is warranted, and in the end, so what? With more research, perhaps a more comprehensive theoretical perspective on motivation in sport can be outlined that includes the presence of historic theory as well contemporary theory. By accounting for the possible overlap between contemporary and historic motivational theory, a more complete framework of motivation may be developed. But how will theory actively assist coaches and sport psychology practitioners?

Beyond theory, assessing what successful coaches do to motivate their players could benefit the work of other coaches as well as sport psychology consultants. The data and results articulated herein could serve to inspire less accomplished coaches to consider their motivational efforts, modify their approaches and practices, and strengthen possible weaknesses. Similarly, sport psychology consultants who focus solely on achievement goals, attributions, and intrinsic and extrinsic motives may be missing out on big picture opportunities to motivate and inspire others. By addressing the meaning that participating in a sport can have to an individual, instigating the human impulse to excel and advance, and drawing on the power of the team to succeed, coaches and sport psychology consultants may be more comprehensive and potentially more successful in their efforts to motivate.

\section{Summary}

A focus on broader and more traditional motivational constructs need not compete with more contemporary research and theory. In fact, they should be more closely aligned. By recognizing the existence of more traditional and global motivational constructs (e.g., pursuing meaning in something larger than the self, working toward individual excellence while 
advancing the social construct, advancing and actualizing the self) within the athletic arena, individuals may gain a broader sense of what motivation is, and how to better motivate oneself and others. In short, more traditional concepts may prove vital to establishing a powerful motivational climate, a cohesive and inspired team, or tying an individual into the vision of the whole. To this end, integrating both historic and contemporary models may advance a more comprehensive conception of motivation in sport.

There may be common motivational themes that coaches are actively employing, yet researchers are seldom exploring. By addressing this perceived discrepancy, there is an opportunity to explore a motivational phenomenon that could prove beneficial for a variety of groups. Further analysis of the motivational practices employed by expert athletic coaches, how successful coaches tap into fundamental human motives, and the motivational value of a socially rich culture that promotes individual success could prove valuable for coaches and athletes alike. Similarly, sport psychology consultants may be able to refine and improve their approaches to motivating athletes and teams toward continued effort and success. 


\section{References}

Adler, A. (1998). Understanding life (Colin Brett, Ed.). MN: Hazelden. (Original work published 1927)

Adegbesan, O. A. (2001). Analysis of psyching-up techniques used with athletes in Nigerian universities. ICHPER-SD journal: The official magazine of the International Council for Health, Physical Education, Recreation, Sport, and Dance, 37(3), 50-52.

Ames, C., \& Archer, J. (1988). Achievement goals in the classroom: Students’ learning strategies and motivation processes. Journal of Educational Psychology, 80(3), 260-267.

Ansbacher, H., \& Ansbacher, R. R. (Eds.). (1964). The individual psychology of Alfred Adler: Systematic presentation in selections from his writings. New York, NY: Harper \& Row, Publishers. (Original work published 1956)

Biddle, S. J. H., Hanrahan, S. J., \& Sellars, C. N. (2001). Attributions: Past, present, and future. In R. N. Singer, H. A. Hausenblas, \& C. M. Janelle (Eds.), Handbook of sport psychology ( $2^{\text {nd }}$ ed., pp. 444-471). New York, NY: John Wiley \& Sons, Inc.

Bloom, G. A., Durand-Bush, N., \& Salmela, J. H. (1997). Pre-and postcompetition routines of expert coaches and team sports. The Sport Psychologist, 11, 127-141.

Bloom, G. A., \& Salmela, J. H. (2000). Personal characteristics of expert team sport coaches. Journal of Sport Pedagogy, 6(2), 56-76.

Bogdan, R. C., \& Biklen, S. K. (1992). Qualitative research for education: An introduction to theory and methods ( $2^{\text {nd }}$ ed.). Boston, MA: Allyn and Bacon.

Botterill, C. (2005). Competitive drive: Embracing positive rivalries. In S. Murphy (Ed.), The sport psych handbook (pp. 37-48). Champaign, IL: Human Kinetics.

Cain, K. M., \& Dweck, C. S. (1995). The relation between motivational patterns and 
achievement cognitions through the elementary school years. Merrill-Palmer Quarterly, 41(1), 25-52.

Campbell, J. (2003). The hero's journey: Joseph Campbell on his life and work (Centennial Edition). Navato, CA: New World Library.

Camus, A. (1991). The myth of Sisyphus and other essays (J. O’Brien, Trans.). New York, NY: Vintage International. (Original work published 1955)

Csikszentmihalyi, M. (1990). Flow: The psychology of optimal experience. New York, NY: Harper Perennial.

Duda, J. L., Chi, L., Newton, M. L., Walling, M. D., \& Catley, D. (1995). Task and ego orientation and intrinsic motivation in sport. International Journal of Sport Psychology, 26, 40-63.

Duda, J. L., \& Hall, J. (2001). Achievement goal theory in sport: Recent extensions and future directions. In R. N. Singer, H. A. Hausenblas, \& C. M. Janelle (Eds.), Handbook of sport psychology ( $2^{\text {nd }}$ ed., pp. 417-443). New York, NY: John Wiley \& Sons, Inc.

Duda, J. L., \& Nicholls, J. G. (1992). Dimensions of achievement motivation in schoolwork and sport. Journal of Educational Psychology, 84(3), 290-299.

Duda, J. L., \& Treasure, D. C. (2001). Toward optimal motivation in sport: Fostering athletes' competence and sense of control. In J. M. Williams (Ed.), Applied sport psychology: Personal growth to peak performance ( $4^{\text {th }}$ ed., pp. 43-62). Mountain View, CA: Mayfield Publishing Company.

Dweck, C. S. (1986). Motivational processes affecting learning. American Psychologist, 41(10), 1040-1048.

Dweck, C. S. (1992). The study of goals in psychology. American Psychological Society, 3(3), 
165-167.

Dweck, C. S. (2006). Mindset: The new psychology of success. New York, NY: Random House.

Eliot, J. F. (2005). Motivation: The need to achieve. In S. Murphy (Ed.), The sport psych handbook (pp. 1-18). Champaign, IL: Human Kinetics.

Elliott, E. S., \& Dweck, C. S. (1988). Goals: An approach to motivation and achievement. Journal of Personality and Social Psychology, 54(1), 5-12.

Frankl, V. E. (1984). Man's search for meaning. New York, NY: Pocket Books. (Original work published 1946)

Frankl, V. E. (1988). The will to meaning: Foundations and applications of logotherapy, expanded edition. New York, NY: Meridian. (Original work published 1969)

Grant, H. \& Dweck, C. S. (2003). Clarifying achievement goals and their impact. Journal of Personality and Social Psychology, 85(3), 541-553.

Griffith, B. A., \& Graham, C. C. (2004). Meeting needs and making meaning: The pursuit of goals. Journal of Individual Psychology, 60(1), 25-41.

Halberstam, D. (2005). The education of a coach. New York, NY: Hyperion.

Hardy, C. J., Burke, K. L., \& Crace, R. K. (2005). Coaching: an effective communication system. In S. Murphy (Ed.), Sport Psychology Handbook (pp. 191-212).

Harwood, C. (2005). Goals: More than just the score. In S. Murphy (Ed.), The sport psych handbook (pp. 19-36). Champaign, IL: Human Kinetics.

Hatch, J. A. (2002). Doing qualitative research in education settings. Albany, NY: State University of New York Press.

Hong, Y., Dweck, C. S., Chiu, C., Lin, D. M. S., \& Wan, W. (1999). Implicit theories, 
attributions, and coping: A meaning system approach. Journal of Personality and Social Psychology, 77(3), 588-599.

Jackson, P., \& Delehanty, H. (1995). Sacred hoops: Sacred lessons of a hardwood warrior (1 ${ }^{\text {st }}$ Paperback ed.). New York, NY: Hyperion.

LaxPower. (2008, a). College computer rating: NCAA Division I. Retrieved March 15, 2008, from http://www.laxpower.com/update08/binmen/rating01.php

LaxPower. (2008, b). College computer rating: Women's Division I. Retrieved March 15, 2008, from http://www.laxpower.com/update08/binwom/rating01.php

LaxPower. (2008, c). NCAA 2008 Men’s Division I Championship. Retrieved March 15, 2008, from http://www.laxpower.com/update08/tourney08/Bracket-MD1.PDF

LaxPower. (2008, d). NCAA 2008 Women’s Division I Championship. Retrieved March 15, 2008, from http://www.laxpower.com/update08/tourney08/Bracket-WD1.PDF

LaxPower. (2008, e). NCAA 2008 Women's Division III. Retrieved October 2, 2008, from http://www.laxpower.com/update08/binwom/rating03.php

LaxPower. (2008, f). NCAA 2008 Men's Division III. Retrieved October 2, 2008, from http://www.laxpower.com/update08/binmen/rating03.php

LaxPower. (2008, g). NCAA 2008 Men’s Division III Championship. Retrieved October 2, 2008, from http://www.laxpower.com/update08/tourney08/Bracket-MD3.PDF

LaxPower. (2008, h). NCAA 2008 Women’s Division III Championship. Retrieved October 2, 2008, from http://www.laxpower.com/update08/tourney08/Bracket-WD3.PDF

Leidl, D. J., \& Frontiera, J. (2007). Team culture: A qualitative analysis of coaches' perceptions of team culture in lacrosse. Unpublished manuscript.

Leidl, D. J., Frontiera, J. \& Siestreem, J. (2008). Motivation: A qualitative analysis of 
motivational strategies employed by elite lacrosse coaches. Manuscript submitted for publication.

Manaster, G. J., \& Corsini, R. J., (1982). Individual psychology: Theory and practice. Itaska, IL: F. E. Peacock Publishers, Inc.

Marx, J. (2003). Season of life. New York, NY: Simon \& Schuster.

Maslow, A. H. (1962). Toward a psychology of being. Princeton, NJ: An Insight Book, D. Van Nostrand Company, Inc.

Maslow, A. H. (1970, a). Religions, values, and peak-experiences. New York, NY: Penguin Compass. (Original work published 1964)

Maslow, A. H. (1970, b). Motivation and personality ( $2^{\text {nd }}$ ed.). New York, NY: Harper \& Row Publishers.

Maslow, A. H. (1971). The farther reaches of human nature. New York, NY: Penguin Compass.

Merriam, S. B. (2002) Qualitative research in practice: Examples for discussion and analysis. San Francisco, CA: Jossey-Bass.

Mueller, C. M., \& Dweck, C. S. (1998). Praise for intelligence can undermine children’s motivation and performance. Journal of Personality and Social Psychology, 75(1), 3352.

Nater, S., \& Gallimore, R. (2006). You haven't taught until they have learned. Morgantown, WV: Fitness Information Technology.

NCAA. (2007). Official 2007 NCAA Men's and Women's Lacrosse Records Book. Retrieved 
March 13, 2008, from

http://www.ncaa.org/library/records/lacrosse/lacrosse_records_book/2007/2007_m_w_la crosse_records.pdf

NCAA. (2008). Official 2008 NCAA Men's and Women's Lacrosse Records Book. Retrieved October 29, 2008, from http://www.ncaapublications.com/Uploads/PDF/2008_m_w_lacrosse_records4f4d8d28bf00-480f-addf-5dc3aa3925d5.pdf

Nicholls, J. G., Patashnick, M., \& Nolen, S. B. (1985). Adolescents' theories of education. Journal of Educational Psychology, 77(6), 683-692.

Patton, M. Q. (2002). Qualitative research \& evaluation methods (3 ${ }^{\text {rd }}$ ed.). Thousand Oaks, CA: Sage Publications, Inc.

Segrave, J. O. (2000). Sport as escape. Journal of Sport \& Social Issues, 24(1), 61-77.

Singer, R. N., \& Orbach, I. (1999). Persistence, Excellence, and Fulfillment. In R. Lidor \& M. Bar-Eli (Eds.), Sport psychology: Linking theory and practice (pp. 167-190).

Smiley, P. A., \& Dweck, C. S. (1994). Individual differences in achievement goals among young children. Child Development, 65, 1723-1743.

Smith, S. L., Fry, M. D., Ethington, C. A., \& Li, Y. (2005). The effect of female athletes' perceptions of their coaches’ behaviors on their perceptions of the motivational climate. Journal of Applied Sport Psychology, 17, 170-177.

Strauss, A., \& Corbin, J. (1990). Basics of qualitative research: Grounded theory procedures and techniques. Newbury Park, CA: Sage Publications, Inc.

US Lacrosse. (2006). US Lacrosse participation survey 2006. Retrieved February 7, 2008, from http://www.uslacrosse.org/pdf/06participationsurvey.pdf 
Vallerand, R. J., \& Perreault, S. (1999). Intrinsic and extrinsic motivation in sport: Toward a hierarchical model. In R. Lidor \& M. Bar-Eli (Eds.), Sport psychology: Linking theory and practice (pp. 191-213). Morgantown, WV: Fitness Information Technology, Inc.

Vallerand, R. J., \& Rousseau, F. L. (2001). Intrinsic and extrinsic motivation in sport and exercise: A review using the hierarchical model of intrinsic and extrinsic motivation. In R. N. Singer, H. A. Hausenblas, \& C. M. Janelle (Eds.), Handbook of sport psychology ( $2^{\text {nd }}$ ed., pp. 389-416). New York, NY: John Wiley \& Sons, Inc.

Vargas-Tonsing, T. M. (2004). An examination of pre-game speeches and their effectiveness in increasing athletes’ levels of self-efficacy and emotion. Published Doctoral Thesis, Michigan State University. Eugene, OR: Kinesiology Publications, University of Oregon.

Vennum Jr., T. (n.d.). History of Native American Lacrosse. Retrieved February 28, 2008, from http://www.uslacrosse.org/museum/history.phtml

Wooden, J. R., \& Jamison, S. (1997). Wooden: A lifetime of observations and reflections on and off the court. Chicago, IL: Contemporary Books. 
Motivation, Achievement, and Coaching 38

Appendix A

Interview Protocol 


\section{Interview Protocol}

1. Describe your history with lacrosse?

- What drew you to the sport?

- In what capacities have you been involved (e.g., player, coach, administrator)?

- What led you to coaching?

2. From your perspective, could you describe the culture of lacrosse?

- Its history?

- Values?

- Attitudes?

3. How is the culture of lacrosse (i.e., its history, values and attitudes) reflected in your coaching?

- How do you draw on this culture to motivate your players?

- How is this culture reflected in your team?

4. Describe your approach to motivating others (e.g., athletes, staff, etc.), and yourself?

5. Describe how you motivate your players?

- How does the history and culture of lacrosse perhaps influence this approach?

- How do team traditions perhaps influence this approach?

- How does your personal history perhaps influence this approach?

- How do stories/goals etc. perhaps influence this approach?

6. What motivates you as a coach?

7. What specific behaviors or practices do you find useful to motivate your players and/or yourself?

8. How would you describe your goals as a coach?

9. What do you do to achieve your goals?

- Specific behaviors. . . 
Motivation, Achievement, and Coaching 40

\section{Appendix B}

Demographic Form 


\section{Demographic Form}

Gender Male___ Female___ Age

Years Coaching

What Level(s)

Years Coaching the Program you won the National Championship With

Did you play lacrosse? Yes_ No__ What Level(s)

Academic background:

Undergraduate Degree (subject):

Masters Degree (subject):

Additional Degrees/Training (subject):

Any education in sport psychology?

Yes__ No 
Motivation, Achievement, and Coaching 42

\section{Appendix C}

IRB Participation Letter 


\section{Daniel J. Leidl, MA \\ West Virginia University \\ Sport and Exercise Psychology \\ Cell Phone (516) 297-2466 \\ Home Phone (304) 296-1122 \\ dleidl@yahoo.com}

March 13, 2008

\section{Dear Participant:}

My name is Dan Leidl, and I am a doctoral student in the Sport and Exercise Psychology program in the School of Physical Education at West Virginia University. I am currently researching motivation in sport, and am engaged in this research in an effort to fulfill requirements associated with a dissertation project that will take place throughout the summer and fall of 2008. I will be interviewing men's and women's lacrosse coaches who have won a National Championship, and have identified you as a participant.

In participating in this research project, I will ask you to engage in a taped interview, in which we will discuss motivation, motivators that trigger you, and methods you use to motivate. Due to the nature of the research I am conducting, disclosure of your identity, as an established participant and contributor to the culture of lacrosse, in any publication or presentation associated with this research will lend credence to the responses you provide during the initial interview and will be included. Please know that you are free to decline an interview, decline answering any questions, and stop the interview at any time. Participation is voluntary, and should you decline or revoke your participation, at no time will your name be associated with this research or your status as a professional be affected.

Thank you for your time and assistance,

Dan Leidl 
Motivation, Achievement, and Coaching 44

Appendix D

Participant Profiles 
Figure D1. Female participants.

\section{Coach 1}

Coach 1's coaching career spans 34 years and bridges four decades. For 32 of those years, she has been at the helm of one of the most successful lacrosse programs in any NCAA division. Her teams have compiled five National Championships, four perfect seasons, and scores of celebrated players. She has been intimately a part of the unfathomable growth in the women's game, and witnessed the powerful impact of Title IX firsthand: assisting her first team in making their own kilts and sticks, to being sponsored by one of the largest equipment manufacturers in the game. She exudes an infectious energy and passion, and presents herself as open, sincere, insightful, and incredibly committed to the game and its growth.

\section{Coach 2}

Coach 2's intensity is palpable. Her eyes, her posture, her presence, all seemingly emanate a hunger to succeed, a drive to achieve. Her persistence and commitment to the game of lacrosse are starkly visible in her playing and coaching careers. As a player she represented the United States as a member of the National Team, persisting through earlier cuts and injuries to eventually make the quadrennial World Cup squad in 1993. As a coach she seems committed to her own growth, and devoted to developing dynamic teams that succeed within the context of a larger system. She has been coaching 23 years, 14 of which have been at her current institution, where her near $77 \%$ winning average and 2003 NCAA Championship place her in the elite ranks of the sports greats.

\section{Coach 3}

Coach 3 presented a humble and team-centered perspective, explaining her success as a product of the efforts of those around her and the luck that has been bestowed upon her. Her office area is shared with her assistants, her walls and shelves are adorned with numerous team trophies and player certificates, and her desk is filled with photos of family and friends. Her career started and continues at a celebrated university where she has been the head coach for 13 years, an assistant the three years prior to that, and a National Championship player prior to that. Her success includes winning the National Championship as a head coach in 2004, participating in the NCAA tournament every year of her tenure, claiming five conference titles, and mentoring some of the most explosive and creative players in the history of the women's game. 
Figure D2. Male participants.

\section{Coach 4}

Coach 4 has won more lacrosse games as a coach than any other men's coach in the history of the game. He has been the head coach of his team for the last 20 seasons, has a record of 321-30, a stunning winning percentage north of $90 \%$, and is currently riding an NCAA-record 77 game, regularseason win streak. He has guided his teams to eight National Championships and 14 Conference Championships, coached scores of All-Americans, 8 National Player's of the Year, 32 Position Player's of the Year, and currently has 45 straight wins and a record of 124-2 throughout the past six seasons. He is a confident and energetic man, whose passion for lacrosse and the success of his team are visible in his office décor, his lively presence, his commitment to the study and practice of coaching, and his candid commentary.

\section{Coach 5}

Coach 5's achievements are record breaking, and his focus and determination to achieve more is nothing short of stunning. An intimidating and intense man, Coach 5's stature, pristine office, and accolades are all a reflection of his attention to detail and laser-like focus. He wants to succeed, and succeed he does. As a player, he won a National Championship, three First Team All-American awards, two Defensive Player of the Year awards, one Player of the Year Award, was a two-time selection to the US National Team, and was honored as the Most Outstanding Player of the 1990 World Games. While he has only been coaching for 19 years, he has been honored as the National Coach of the Year at both Division I schools he has coached at, has won two National Championships in his current position, has the second highest winning percentage among active Division I coaches, and has orchestrated a return to glory for his program.

\section{Coach 6}

Coach 6's intelligence and charisma are quickly evident, and there is little surprise that his openminded approach annually attracts some of the most creative and talented young players in the nation. An Ivy League graduate, he has become one of the most influential coaches of his time, leading both the schools he has worked with to stunning levels of success. He has won three National Championships, all with his current program, and is regularly a favorite to take home another. In his 16 seasons at his current school, he has reached the NCAA Tournament 15 times, has won five conference championships, has a winning percentage of nearly $75 \%$, and has coached some of the most stunning young players to have played the game.

\section{Coach 7}

As the one of the game's all-time greats, Coach 7 offers a patient, humble, and seasoned perspective. He has been coaching for 30 years, has won Championships as an assistant and head coach, and has worked with some of the greatest teams, coaches, and players in the history of the collegiate lacrosse. He won three National Championships in 1984, 1985, and 1987 at the first school he coached for, and has been the head coach with his current program since 1994. As the architect of his current program's success and ascension toward being a national power, he is building on some of the most successful seasons in the school's history. His office is somewhat barren, but a photo of his family and a photo of his team standing atop a mountain seem to say volumes about his focus and commitment. 
Motivation, Achievement, and Coaching 47

Appendix E

Demographic Data Form 
Motivation, Achievement, and Coaching 48

\begin{tabular}{|c|c|c|c|c|c|c|c|}
\hline \multicolumn{8}{|c|}{ Demographic Data Form } \\
\hline ID & Gender & Age & $\begin{array}{c}\text { Years } \\
\text { Coaching }\end{array}$ & Levels Coached & $\begin{array}{l}\text { Years where } \\
\text { Won }\end{array}$ & $\begin{array}{l}\text { Played Lacrosse } \\
\text { (Y/N) }\end{array}$ & Levels Played \\
\hline Coach 1 & $\mathrm{~F}$ & 55 & 34 & $\begin{array}{l}\text { HS/NCAA - Div } \\
\text { III }\end{array}$ & 32 & $\mathrm{Y}$ & College \\
\hline Coach 2 & $\mathrm{~F}$ & 40 & 16 & NCAA - Div I & 13 & $\mathrm{Y}$ & HS, Collge, Division I \\
\hline Coach 3 & $\mathrm{~F}$ & & 23 & $\begin{array}{l}\text { HS/NCAA - Div } \\
\text { III }\end{array}$ & 14 & $\mathrm{Y}$ & $\begin{array}{l}\text { HS, College, Division I, US } \\
\text { World Cup }\end{array}$ \\
\hline Coach 4 & M & 48 & 26 & NCAA - Div III & 20 & $\mathrm{Y}$ & HS, College, Division I \\
\hline Coach 5 & M & 40 & 19 & $\begin{array}{l}\text { HS/NCAA - Div } \\
\text { I }\end{array}$ & $\begin{array}{l}9 \mathrm{Head} / 3 \\
\text { Assistant }\end{array}$ & $\mathrm{Y}$ & $\begin{array}{c}\text { HS, College, Division I, US } \\
\text { National Team }\end{array}$ \\
\hline Coach 6 & M & 56 & 34 & NCAA - Div I & 16 & $\mathrm{Y}$ & College, Division I \\
\hline Coach 7 & M & 55 & 30 & $\begin{array}{l}\text { HS/NCAA - Div } \\
\text { I }\end{array}$ & 7 & $\mathrm{Y}$ & HS, College, Division I \\
\hline
\end{tabular}


Motivation, Achievement, and Coaching 49

Appendix F

Review of Literature 


\section{CHAPTER 2}

Review of Literature

\section{Introduction}

"Each of us has a picture, however vague, of what we would like to accomplish before we die. How close we get to attaining this goal becomes the measure for the quality of our lives.” (Csikszentimihalyi,1990, p. 9)

Although there would seem to be more to the issue of motivation than captured in his statement, perhaps Csikszentimihalyi’s (1990) words ring somewhat true. Perhaps human beings are guided by a vague vision of what they believe they are capable of becoming or what they are capable of accomplishing. It may even be that we are not only guided by our goals, but our satisfaction in life is achieved in accordance with accomplishing whatever it is we have set our sights on. Perhaps our lives are nothing more than a continual effort to achieve something through life so as to find satisfaction within it.

While such language and philosophical musings may harbor a profound truth, they are rarely incorporated into the zeitgeist of contemporary sport psychology. As discussed throughout the Introduction, much of the focus on motivation in sport pertains to specific motivational issues related to achievement goals (Cain \& Dweck, 1995; Duda \& Hall, 2001; Duda \& Nicholls, 1992; Elliott \& Dweck, 1988; Grant \& Dweck, 2003; Nicholls, Patashnick, \& Nolen, 1985), intrinsic and extrinsic motivation (Botterill, 2005; Eliot, 2005; Smith, 2001; Vallerand \& Perreault, 1999; Vallerand \& Rousseau, 2001), and attribution theory (Biddle, Hanrahan, \& Sellars, 2001; Duda \& Treasure, 2001; Eliot, 2005; Singer \& Orbach, 1999). Such constructs have expanded theory and research regarding athletes' motives to perform at increased 
or decreased levels of exhilaration and effort, but seem to overlook a more fundamental starting point: What attracts one to sport in the first place?

With regard to Csikszentimihalyi’s (1990) opening quote, perhaps research pertaining to motivation in sport overlooks a deeper philosophical perspective. Perhaps researchers would benefit from stepping back, viewing the issue from a more global vantage point. Perhaps researchers should adjust their perspectives, enquiring less about an individual's intrinsic and extrinsic motives or task and ego orientations, and more about what has attracted an individual to those cues in the first place. While much has been written and researched about how to optimally motivate a team, little has been explored regarding why a team would show up to practice, let alone want to perform. In assessing these more expansive issues, perhaps a more contextualized perspective of motivation in sport can be developed. Perhaps we could improve our research approach by gaining further insight into why sport is attractive to human beings in the first place, and if coaches are capable of drawing on those impulses to augment motivation.

The notion that human beings are seemingly compelled to express themselves in the context of something that extends beyond the self has been the subject of psychological theory for decades (Adler, 1927/1998; Ansbacher \& Ansbacher, 1956/1964; Frankl, 1946/1984, 1969/1988; Manaster \& Corsini, 1982; Maslow, 1962, 1964/1970, 1970, 1971). Yet questions related to the attractiveness of sport as a medium, the drive to express the self through sport, the willingness to sacrifice in the name of sport are seemingly overlooked with regard to guiding contemporary motivational theory and research in sport psychology. Regardless, it would seem that sport psychology is an appropriate and fertile discipline to study such queries, as there are few places in contemporary society where individuals invest as much of themselves through a 
medium without engaging in actual war (e.g., risking time, money, interpersonal conflict, safety, etc.).

Although such thoughts are a departure from current research, they are truly the stuff of a rich and historic body of psychological theory that has been seemingly overlooked by contemporary sport psychologists (Adler, 1927/1998; Ansbacher \& Ansbacher, 1956/1964; Frankl, 1946/1984, 1969/1988; Manaster \& Corsini, 1982; Maslow, 1962, 1964/1970, 1970, 1971). In reviewing three historic motivational theorists, perhaps a clearer picture of what contemporary sport psychology may be missing in regard to motivation in sport can be elucidated. Adler, Frankl, and Maslow have all made significant contributions to the philosophical conception that human beings are psychologically driven to interact with others, pursue happiness through engaging in the world around them, and advance and express the self through the context of a medium that extends beyond the self (Adler, 1927/1998; Ansbacher \& Ansbacher, 1956/1964; Frankl, 1946/1984, 1969/1988; Manaster \& Corsini, 1982; Maslow, 1962, 1964/1970, 1970, 1971). In further exploring the nuances of these theoretical conceptions, a more detailed perspective of what seems to be missing from contemporary sport psychology theory related to motivation may become clear. There appears to be a significant gap between contemporary theory related to motivation in sport, and more historical theoretical perspectives. Such a gap warrants narrowing, but must first be further defined. It has long been argued that human beings are compelled to advance the self within the context of a medium that extends beyond the individual (Adler, 1927/1998; Ansbacher \& Ansbacher, 1956/1964; Frankl, 1946/1984, 1969/1988; Manaster \& Corsini, 1982; Maslow, 1962, 1964/1970, 1970, 1971), but there remain numerous questions regarding if and how sport can satiate such urges and how motivational strategies within sport can be advanced in regard to such concepts. To follow are 
three conceptualizations of motivational theories that may spark further insight into the baser motives that attract individuals to sport. Additionally, these theories will serve to further define the gap that seems to separate contemporary and historical theory, and assist to define a direction for future study.

\section{Motivation Theory - Three Historic Perspectives}

Frankl and the Existentialists - The Pursuit for Meaning

In his seminal work, Man’s Search for Meaning, Victor Frankl (1946/1984) stated:

Man’s search for meaning is the primary motivation in his life and not a ‘secondary rationalization’ of instinctual drives. This meaning is unique and specific in that it must be filled by him alone; only then does it achieve a significance which will satisfy his own will to meaning. (p. 121)

For Frankl, man is self determined, enhancing and devising life’s meaning one decision at a time by persisting, suffering, basking in the salvation of love, and experiencing the music, art, poetry and culture life inspires. Meaning is found in the greatest of hardships and triumphs, for, “human life, under any circumstances, never ceases to have a meaning” (Frankl, 1946/1984, p. 104).

Frankl's conception of human motivation revolves around two basic conditions related to existential theory. Nietzsche (1885/1969) forcefully proclaimed the first condition when he declared the death of God in Thus Spoke Zarathustra when it was first published around 1885. With this proclamation, human beings were suggested to be on their own, no longer governed directly or indirectly by the will of a higher power. As the century turned and Zarathustra raged, metaphysical problems became more significant as individuals became increasingly engrossed 
with the possibility that their existence may not be governed by a higher moral order (Camus, 1955/1991). This shift in theoretical focus dropped humankind into a sea of possibility, but with the loss of an impending afterlife and/or Godlike scrutiny, there was no longer a modicum of certainty with regard to where one could end up once s/he began to swim.

The second condition is a direct result of the first, as self determined individuals have the distinct charge of creating a life of purpose and value without the assistance of a higher order or impending afterlife. Such philosophical possibilities of autonomy and self governance were accompanied by sincere and profound concern. Modern man’s obligations to life had somehow increased, as the weight of his experience lay solely on his/her shoulders. As Sartre (1947/1974) noted with his cautionary sketch of an unsatisfied man: "I have led a toothless life. . .A toothless life. I have never bitten into anything. I was waiting. I was reserving myself for later on - and I have just noticed that my teeth have gone. What's to be done?” (p. 244). With this point in mind, how is man to live a life of significance without the guidance of a higher power, the assistance of Godlike order?

Frankl (1946/1984, 1969/1988) and the existentialists respond to queries regarding the significance of life by assuring that the human experience is alive with meaning and value. Life is an opportunity to soak up the stimulation that surrounds us, and ingest the happenings that occur every moment throughout our existence. For Nietzsche (1885/1969), such a position led to opportunity, and he implored humanity to "Be of good courage, what does it matter! How much is still possible. . . oh how much is still possible?! And truly, how much has already succeeded!” (p.303). Meaning makes up the treasured details that stay with us throughout our lifetime: a walk through a forest, a favorite song, the sweet crack of biting into an apple, a first kiss (Camus, 1948/1975; Frankl, 1969/1988). And meaning can also be found in the search for beauty and 
purpose in the face of unspeakable struggle (Camus, 1948/1975, 1955/1991; Frankl, 1969/1988). Drawing on his personal experiences in a Nazi Concentration Camp, Frankl (1946/1984) stated, "we could say that most men in a concentration camp believed that the real opportunities of life had passed. Yet, in reality, there was an opportunity and a challenge. One could make a victory of those experiences turning life into an inner triumph” (p. 93).

For Frankl and the existentialists, without the guidance of a higher order, human beings are motivated to construct a life rich with meaning, defining life in the context of experiences and observations. Even during times of hardship one has the opportunity to extend his/her understanding of him/herself by overcoming challenges and ending each journey with, “achievement, triumph, and heroism” (Frankl, 1969/1988, p. 70). Human beings are motivated to continually search for and identify meaning through life, perpetuating an understanding of purpose in a self-determined world. In good times or bad, we are defining ourselves in the context of our experiences, and relying on the profundity and perception of such experiences to motivate our efforts, goals, and even our willingness to continue living.

In articulating human motivation as a pursuit for meaning, how does such a pursuit apply to athletics? Such questions have rarely been pondered, but how does sport add meaning to life? How do coaches work to infuse meaning into the journey of a season, the career of a player, the triumphs of a team? In defining motivation in such terms, how does the human quest for meaning motivate players and coaches to pursue sport as careers, pursue a degree of excellence through sport, pursue a life in sport? Frankl's (1946/1984, 1969/1988) conception of motivation is seemingly global in scope, but would appear to have a number of implications when applied directly to the world of sport. In viewing Frankl’s (1946/1984, 1969/1988) theoretical 
conception in conjunction with two additional perspectives (i.e., Adler and Maslow) similar questions related to motivation and athletics develop.

Alfred Adler - The Pursuit for Perfection

Adler, similar to Frankl, theorizes that motivation is contingent on a human drive to pursue something of value. Recently, arguments have suggested that existential theory and Adlerian theory are mutually beneficial and share significant similarities (Hjertaas, 2004; Mosak \& Dreikurs, 2000), but distinctions should not be overlooked. Frankl (1948/1984, 1969/1988) suggests that humans are motivated by a search for meaning, as they are driven by the existential dilemma of living a self-determined purposeful life. However, in accordance with Adler's perspective, “. . .the human condition is the perpetual striving for superiority or overcoming, a goal that arises from the state of vulnerability, inferiority, or incompletion.” (Griffith \& Graham, 2004, p. 26). Thus, the primary motive behind human striving for Adler is an urge to overcome inferiority through a pursuit for perfection (Ansbacher \& Ansbacher, 1956/1964; Ashby \& Kottman, 1996; Goldwert, 1984; Griffith \& Graham, 2004; Lazarsfeld, 1991; Manaster \& Corsini, 1982; Watts \& Holden, 1994), while Frankl’s (1948/1984, 1969/1988) conception of human motivation is contingent on man’s self-determined quest for meaning.

At our birth we are lesser in stature, mind, and power to the more developed world around us. Children are inherently intellectually, emotionally, and physically inferior to the parents, teachers, taskmasters, and authority figures who govern, direct, and lead them. As we age we are reminded of our diminutive physical stature and presence in the face of the larger world and cosmos that engulf us, and even in our intellectual pursuits we are continuously reminded of our flaws and inabilities. "[A]ll our human culture is based upon feelings of inferiority” (Ansbacher \& Ansbacher, 1956/1964, p. 117), and it is this pervasive sense of 
inferiority that motivates us to strive toward a greater end (Ashby \& Kottman, 1996; Ferguson, 2003; Griffith \& Graham, 2004; Lazarsfeld, 1991).

The logical end to any striving is a finalization of the task at hand, or in a more global sense, an achievement of perfection. However, such an achievement in Adlerian terms is meaningless if it is not socially relevant (Ashby \& Kottman, 1996; Hjertaas, 2004; Mosak \& Dreikurs, 2000). Human beings are driven to overcome inferiority by striving forward in the pursuit of socially meaningful goals (Ferguson, 2003; Griffith \& Graham, 2004). "Striving for perfection means to move in the direction of social interest, in line with the common sense of communal living, toward greater competence” (Manaster \& Corsini, 1982, p. 75). Adler suggested that the human motivation to strive forward is directed and governed by society, further suggesting, “. . . all that endures and continues to endure, is eternally the product of social interest” (Ansbacher \& Ansbacher, 1956/1964, p. 107).

While goals vary from one person to the next, they all keep us motivated toward a future end (Adler, 1927/1998; Griffith \& Graham, 2004). As Ferguson noted, “The social-symbolic aspect of goals allows individuals to be future-oriented, to make choices and develop supportive human relationships that enable the person to make the future an improvement over the past” (2003, p. 138). Human diversity in life experience logically explains variance in human goals, and individuals seek to overcome inferiority through individualized goals and means (Griffith \& Graham, 2004). Additionally, the pursuit of such individual goals may not be perceived as positive and/or good by anyone beyond the individual him/herself (Ashby \& Kottman, 1996). For example, "If a person is consistently pathetic, inept, clumsy, and stupid in everything he tackles, so that he is never asked by anyone to do anything. Adlerians conclude that this is precisely the goal of that person.” (Manaster \& Corsini, 1982, p. 178-179). Evil, self loathing, 
and other negative human behaviors are best explained as individual attempts to overcome inferior feelings with goals and actions that ignore and/or shun societal values and needs (Adler, 1927/1998; Ansbacher \& Ansbacher, 1956/1964; Ashby \& Kottman, 1996; Griffith \& Graham, 2004; Manaster \& Corsini, 1982).

Adler's motivational theory is efficiently described as a quest for overcoming inferiority. Man is imperfect by nature, born inferior and developing into an individual who's primary motivation is to overcome his/her feelings of lowliness by striving toward goals that have been defined by his/her societal experiences. Due to the differences in each individual's development and interaction with society, each person harbors varying beliefs as to how to strive beyond inferiority. Regardless of the socially influenced course a human being pursues, all humans are resilient in their efforts to pursue perfection as a guiding beacon in an effort to overcome the inadequacy within his/her life. As Adler stated, “Goals are what motivate us; we perceive them as the best way for us to survive. In general they are what we want or what we believe in our heart of hearts to be the best for us.” (Adler, 1927/1998, p. 3).

In accordance with such perspectives, how do sports offer opportunities for human beings to pursue socially significant goals? How do coaches draw on such principles to motivate their athletes? How do coaches accommodate for the individual objectives of the people they coach? How are teams motivated to come together to pursue group goals, and are those group goals socially relevant? As with Frankl, Adlerian theory insights a number of queries related to motivation and sport, all of which have been given little attention through research and theory. Abraham Maslow - The Pursuit for Self-Actualization

Abraham Maslow’s contributions to motivational theory reshaped the very conception of human motivation. Prior to Maslow, theorists seemed to overly focus on external forces that 
drive human motivation. Frankl (1946/1984; 1969/1988) speaks of the meaning man sojourns to find in an effort to make sense of a solitary existence governed solely by freewill. Adler (Adler, 1927/1998; Ansbacher \& Ansbacher, 1956/1964; Manaster \& Corsini, 1982) argues that man’s pursuit for perfection is driven by social experiences and motivated by innate feelings of inferiority. While these theories express the curious human phenomenon to pursue something beyond life itself, they do so in the context of forces beyond human life. Maslow $(1962,1970)$ takes a significant step back, and begins his theory of human motivation with the human desire to survive.

Unlike Frankl and Adler, Maslow (1970) essentially defined human motivation in purely human terms (Or at least did so until the final stage of his hierarchy). Maslow’s theory depicts motivation as a hierarchical structure governed by man him/herself, and his/her basic animalistic tendencies. Maslow recognized the inherent power of life and the will to sustain it, and builds his theory of motivation around it. Maslow's (1970) theory of human motivation is generally illustrated as a pyramid divided in five levels, which serves as a motivational hierarchy that coordinates human needs with human function. The motivation to pursue each level of need is contingent upon the satisfaction of needs below it, and man's motivation to achieve higher level needs is much less than his/her motivation to satisfy baser level needs. Theoretically, few humans struggle with the final two levels of the hierarchy, as the initial three motives related to survival often become the focus of human existence.

To follow is Maslow's (1970) hierarchy in a more comprehensive form:

1. Physiological Needs are best defined as those needs that satisfy the conditions of life. Maslow contends that a list of Physiological Needs is futile, as such a list could include details pertaining to the basic survival needs of a mere cell and everything it constructs. 
However, he concludes that Physiological Needs must be met for life to be sustained, and are generally associated with oxygen, food, water, propagating the species through consensual intercourse, etc. Maslow contends that when such needs are not met, human beings are wholly focused on maintaining life by fulfilling such needs. For example, “A person who is lacking food, safety, love, and esteem would most probably hunger for food more strongly than for anything else” (Maslow, 1970, p. 37).

2. Safety Needs are those needs related to an absence of fear and a security for life. In short, when danger threatens, man is primarily motivated to secure his/her wellbeing. Extending beyond this basic concept, Maslow also suggests that man is secondarily motivated to achieve stability, structure, order, fairness, and routine. Humanity does not simply seek the comfort of safety, but a conditional safety, in which structure and routine are possible and present. As Maslow (1970) argued, a human being “. . .generally prefers a safe, orderly, predictable, lawful, organized world, which he can count on and in which unexpected, unmanageable, chaotic, or other dangerous things do not happen. ..” (p. 41).

3. Belongingness and Love Needs refers to the desire in man to surround him/herself with caring relationships. Human beings are social creatures driven to create meaningful, supportive, and reciprocal relationships with other human beings. "If both the physiological and safety needs are fairly well gratified. . .He will hunger for affectionate relations with people. ..” (Maslow, 1970, p. 43).

4. The Esteem Needs relate to humanity’s compulsion, “for a stable, firmly based, usually high evaluation of themselves, for self-respect, or self-esteem, and for the esteem of others.” (Maslow, 1970, p. 45). Maslow (1970) categorized these needs into two groups: "first, the desire for strength, for achievement, for adequacy, for mastery and competence, for 
confidence in the face of the world, and for independence and freedom”(p. 43); and, "Second, we have what we may call the desire for reputation or prestige (defining it as respect or esteem from other people), status, fame and glory, dominance, recognition, attention, importance, dignity, or appreciation.” (p. 43). Upon satisfying the first three levels of Needs, man is then motivated to satisfy his/her desire to impress upon others and him/herself that s/he is a competent individual worthy of society's recognition.

5. The Need for Self-Actualization represents the pinnacle of Maslow's (1970) motivational theory, and represents man's impulse to actualize him/herself in the context of human achievement through an expressive medium. As Maslow stated, "What a man can be, he must be” (Maslow, 1970, p. 46), and at this stage man is driven to determine and express who $\mathrm{s} /$ he is. Sitting atop the metaphorical pyramid, the Need for Self-Actualization is, accordingly, the least likely of the five needs to be satisfied. Those who have satisfied the first four needs will eventually feel motivated to express themselves through a medium that acts as an extension of the self. In this respect, individuals express their individuality through their chosen medium, and no two expressions are identical: “. . . In one individual it may take the form of the desire to be an ideal mother, in another it may be expressed athletically, and in still another it may be expressed in painting pictures or in inventions” (Maslow, 1970, p. 46).

Through the articulation of the five needs, Maslow (1970) devised a theoretical framework that details human motivation beginning with base animalistic needs associated with individual and societal survival, and extending to man's drive to achieve something that extends beyond him/herself. The first four needs emphasize the human motivation to survive, preserve safety 
and security, integrate with other human beings, and preserve social order by adopting and maintaining an appropriate social standing. In categorizing the five needs, the first four needs, “can be conceived as drives towards the reduction of a deficiency", while "Self-actualization, on the other hand, may be called a growth need” (Heylighen, p. 41, 1992).

The fifth need is unique in comparison to the rest of the Hierarchy. In several ways the Need for Self-Actualization is seemingly independent of the first four. In addition to representing human growth as opposed to human deficiency, the fifth need seems best defined as a distinctive theoretical attempt, similar to the theories of Frankl (1946/1984; 1969/1988) and Adler (Adler, 1927/1998; Ansbacher \& Ansbacher, 1956/1964; Manaster \& Corsini, 1982), to articulate motivation in the context of a human drive for something greater than him/herself. Whereas the initial four needs describe human behavior in the context of survival (i.e., individual and societal sustainability), the fifth need is suggestive of a human motive to pursue a level of achievement that extends beyond the everyday (e.g., meeting basic needs).

Maslow articulated the Need for Self-Actualization as the need to discover, define, and actively be oneself, suggesting that self-actualization represents the full expression of an individual’s capabilities (Chang \& Page, 1991; Gundersheim, 1979; Maslow, 1962, 1970, 1971). Similar to Frankl and Adler, Maslow contends that human beings are motivated to advance beyond the self. While Maslow purports that the human motivation to pursue self-actualization is only realized when the four preceding needs are met, self-actualization begins with a human search similar to those described by Frankl and Adler. However, Maslow deviates from Frankl and Adler, expressing the fifth need as neither a striving for perfection nor meaning, as human beings are inspired to fully actualize their individual capabilities, defining and fulfilling their self (Maslow, 1962, 1970, 1971). 
Maslow focused considerable attention on better understanding and describing the Need for Self-Actualization, and attempted to do so by studying various historical and contemporary individuals who he considered to be self-actualized (Maslow, 1970). In an attempt to define selfactualization, Maslow relied on character studies of individuals who represented the small percentage of human beings who seemed to reach a pinnacle of human expression, awareness, and comfort with the self (e.g. Lincoln, Einstein, Huxley) (Maslow, 1970). In describing the traits of the chosen few, Maslow suggests a number of identifiable features (e.g., individuality, creativity, intense sense of morality, ambitiously curious, etc.), but best described these individuals as, "people who have developed or are developing to the full stature of which they are capable” (Maslow, 1970, p.150).

In addition to the various similarities Maslow has defined with regard to self-actualized individuals, he also suggested that the peak-experience is an indication or expression of selfactualized determination or movement (Maslow, 1962, 1964/1970). Peak-experiences are fleeting occurrences in which an individual connects with the self in a way that excludes all stimulation from the outside world with the exception of the task they are engaged in (e.g., writing prose, playing music, painting, etc.). Peak-experiences are often associated with intense focus, a distorted perception of space and time, sensations of full control, feelings of interconnectivity or synchronicity between the self and the engaged task, a high sense of self confidence, intense feelings of emotional and cognitive arousal, and fluid action and/or prolific ability to create (Maslow, 1962; Maslow, 1964/1970; Williams \& Krane, 2001). Maslow suggests that peak-experiences are indicative of an individual's true self, an indication that a higher state is not only possible but is also accessible: “people in peak-experiences are most their identities, closest to their real selves” (Maslow, 1962, p. 97). Through these seemingly mystic 
experiences, human beings become aware and oftentimes connected with their transcendent capacity. While such experiences are not representations of self-actualization, they do serve to suggest that the more expansive state of self-actualization is possible, which encourages human striving toward a more magnificent end that is inherently associated with the wonder and profundity of the peak-experience (Hamel, Leclerc, \& Lefrancois, 2003). In Maslow’s (1964/1970) words, "Thus the peaker learns surely and certainly that life can be worthwhile, that it can be beautiful and valuable. There are ends in life, i.e., experiences which are so precious in themselves as to prove that not everything is a means to some end other than itself.” (p. 75).

Similar to the questions raised by the theoretical conceptions of Frankl and Adler, Maslow's work sparks sincere queries related to motivation and sport. For example, how do sports fulfill the needs and motives that Maslow has articulated? How do coaches work to manipulate an athlete's desire to achieve or define him/herself as a means of motivation? Do peak experiences and the desire to advance the self truly motivate athletes to pursue athletic excellence? Such questions seem relevant and pertinent with regard to motivation in sport, but again few efforts have focused on addressing and exploring them.

Final Words - Frankl, Adler, \& Maslow

While more contemporary theories pertaining to motivation in sport may do well to articulate and identify achievement goals (Cain \& Dweck, 1995; Duda \& Hall, 2001; Duda \& Nicholls, 1992; Elliott \& Dweck, 1988; Grant \& Dweck, 2003; Nicholls, Patashnick, \& Nolen, 1985), intrinsic and extrinsic motivation (Botterill, 2005; Eliot, 2005; Smith, 2001; Vallerand \& Perreault, 1999; Vallerand \& Rousseau, 2001), and attributions (Biddle, Hanrahan, \& Sellars, 2001; Duda \& Treasure, 2001; Eliot, 2005; Singer \& Orbach, 1999), significant questions remain. In assessing the theoretical conceptions of Adler (1927/1998; Ansbacher \& Ansbacher, 
1956/1964; Manaster \& Corsini, 1982), Frankl (1946/1984, 1969/1988), and Maslow (1962, 1964/1970, 1970, 1971), more expansive motivational forces may be at work. Such theories suggest that individuals engaged in sport may be doing so for intricate and complicated purposes that can not be solely explained by contemporary sport psychology theory. In accordance with the theories of Frankl (1946/1984, 1969/1988), Adler (1927/1998; Ansbacher \& Ansbacher, 1956/1964; Manaster \& Corsini, 1982), and Maslow (1962, 1964/1970, 1970, 1971) individuals may engage in sport for deep, psychologically inspired reasons: to find meaning and purpose in life, positively contribute to an organized social milieu, and/or express the essence of oneself through an accessible and inspiring medium.

While there would seem to be a gap in the literature that divides contemporary sport psychology and more traditional theory related to motivation, confounding the lack of study related to the more global motivational ideas put forth by Frankl, Adler, and Maslow is the fact that such concepts seem to be alive and present within the world of sport. Segrave (2000) purported in his essay "Sport as Escape”, one "of sport's seductive charms: it can offer what life often cannot, a clear sense of purpose and meaning” (p. 71). Reflecting on his days as a gifted runner, Joseph Campbell (2003) stated, "I’ve never in my life met an order of young men to match those young men in the athletic arena. They were real human beings.” (p. 223). Campbell (2003) also notes, “That's the mysticism of athletics. . .and the experience is the experience of a truth.” (p. 41). Similarly, books by and about coaching like Sacred Hoops (Jackson \& Delehanty, 1995), Season of Life (Marx, 2003), and The Education of A Coach (Halberstam, 2005) abound with metaphors and anecdotes that directly relate to themes of transcendence, meaning, socially significant pursuits, teamwork, and self actualization. In line with the sentiments of Maslow, Frankl, and Adler, such quotes and larger works suggest that there may be 
good reason to further explore the connections between sport and more traditional motivational constructs.

With regard to the theories of Frankl, Adler, and Maslow, motivation in the context of sport may be a much larger issue than currently presented throughout the discipline of sport psychology. In addressing this possibility, the opportunity to further explore the depths of human motivation that inspire athletic efforts may provide insight into why athletes play and how they can be further motivated to work harder and perform at more inspired levels. It would seem that there is a clear gap between contemporary theory and more historical perspectives, within which a number of motivational keys and insights may lie dormant. As expressed in Moore’s (1970) The Psychology of Athletic Coaching, “The nature of the motivating force may be difficult for the coach to discover. As a matter of fact the boys may be either unable or unwilling to state their personal reasons for reporting, but they are there nevertheless - a group of individuals, all apparently expressing a desire to learn.” (p. 120). As per Moore’s (1970) dated and succinct sentiment, there remains little research or insight with regard to the more global motives that stimulate individual effort in athletics. Such individuals risk safety and well being to perform, spend money and time to be a part of a team, and yet they keep showing up. However, it would seem that as long as those boys or girls keep coming to play, further efforts should be made to understand the seemingly powerful motives that inspire participation in sport in the first place. In working to understand the motivating allure of sport, the reasons people engage in it, and the methods master coaches employ to further motivate action and excellence, one may gain profound insight into human motives that not only correlate with traditional theory but also shed light on techniques, theories, and methods that may extend beyond those detailed in the current literature. 


\section{Coaches as Motivators}

“The essence of coaching comes down to teaching and motivating” (Hardy, Burke, \& Crace, 2005, p. 191). Clearly, the leaders of the sporting world, coaches, are expected to drive, teach, and motivate their teams in the pursuit of success. Weese (1995) contended that, "Leaders impact the culture of their respective organization through their words and actions: what they pay attention to, what they react to, how they coach and encourage others, what they allocate rewards to, and how they influence the recruitment, hiring, training, and termination of staff members” (p. 121). While Weese's study focuses on recreation administrators, the quote seems appropriate for athletic coaches, as their actions and words are intended to inspire their players and staff toward the achievement of on-field success. In their roles as leaders, coaches plan their practices, maintain pre- and post-competition routines, focus on having fun when teaching, advance their knowledge of their sport, review film, and much more in the name of advancing the athletes they lead (Bloom, Durand-Bush, \& Salmela, 1997; Bloom \& Salmela, 2000). Coaches go to great lengths to develop successful teams, working towards the development of ideal social milieus and competitive climates of excellence, and the manners in which they pursue such goals have been observed, researched, and recorded a considerable amount.

Chelladurai has contributed a significant amount of material to the subject of effective coaching, focusing on coaching behavior, effective leadership styles as well as athletes’ leadership preferences (Chelladurai, 1981; Chelladurai, 1984; Chelladurai, 1990; Chelladurai \& Saleh, 1978; Chelladurai \& Saleh, 1980). He emphasized the coach's role as a leader, and suggested that congruence between specific coaching behaviors (i.e., Democratic, Autocratic, Training and Instructional, Social Support, and Positive Feedback) and athletes’ needs and desires can influence athlete satisfaction and performance (Chelladurai, 1984; Chelladurai, 1990, 
Chelladurai \& Saleh, 1978; Chelladurai \& Saleh, 1980). Chelladurai has made considerable contributions toward identifying and objectifying effective coaching styles and strategies. Directly drawing on Chelladurai's work, Weiss and Friedrichs (1986) found that democratic behavior, positive feedback, and socially supportive behaviors are likely to increase athlete satisfaction.

It has been suggested that coaches have the power to impact their teams in a profound and extensive manner through words, actions, and the overall climate they create. Through a qualitative analysis of expert coaches, Bloom, Stevens, and Wickwire (2003) found that coaches maintain a central role in developing teams by employing a variety of strategies to further team chemistry and cohesion. In accordance with research focused on achievement goals (Ames \& Archer, 1988; Cain \& Dweck, 1995; Duda, Chi, Newton, Walling, \& Catley, 1995; Nicholls, Patashnick, \& Bobbit Nolen, 1985) team climates may greatly influence the attitudes and perceptions of athletes. For example, climates that foster task orientation seem to also foster individual enjoyment, interest, and increased effort, whereas those that foster ego orientation seem to leave athletes feeling pressured, anxious, and unenthusiastic (Newton \& Duda, 1999; Newton, Duda, \& Yin, 2000). In other words, teams that emphasize the glory of winning over the enjoyment of playing, punish for poor outcomes before praising for intense efforts, and commend natural ability over efforts to improve are less likely to develop athletes who experience sustained levels of enjoyment, interest, and effort.

In concert with these findings, two studies that focused on the coaches affect on team climates suggest that “athletes’ perceptions of their coaches’ behaviors contribute significantly to their perceptions of the climate” (Smith, Fry, Ethington, \& Li, 2005, p. 176), and the climate a coach develops can even foster more or less aggressive attitudes (Rascale, Coulomb-Cabagno, \& 
Delsarte, 2005). Coaches who are apt to praise more, scold less, and emphasize the importance of correcting mistakes while praising hard work and continued effort are more likely to have athletes who perceive a task oriented climate (Smith et al., 2005). Conversely, coaches who scold more while emphasizing victory and innate ability are more likely to develop ego oriented climates, which seem to promote more aggressive playing styles (Rascale et al., 2005; Smith et al., 2005).

In perhaps one of the most memorable studies related to coaching, Tharp and Gallimore (1976) observed John Wooden coach his UCLA team throughout fifteen basketball practices. With the motive to analyze his coaching techniques, and translate his effective strategies into classroom pedagogy, the Wooden study focused on defining a master coach's specific teaching techniques and delivery (Gallimore \& Tharp, 2004; Tharp \& Gallimore, 1976). Tharp and Gallimore (1976) transcribed and categorized everything they could hear Wooden say during his practices and the results provide tremendous insight into the types of teaching directions and demanding expressions a great coach communicates. Exceptional detail is paid to articulating the variance in Wooden’s many expressions (e.g., scolds, hustles, praise, “Woodens” or modeling positive, modeling negative, modeling positive, etc.), and the findings were revisited in 2004 to further emphasize their pedagogical import (Gallimore \& Tharp, 2004; Tharp \& Gallimore, 1976). Interestingly, in a similar study conducted with basketball coach Jerry Tarkanian, Bloom, Crumpton, and Anderson (1999) found that tactical and technical instructions, coupled with words of encouragement represented more than $50 \%$ of statements recorded during the practices observed throughout an entire season.

In addition to detailing the manner in which Wooden taught his players, Tharp and Gallimore’s (1976; Gallimore \& Tharp, 2004) work also provides insight into the notion that 
Wooden led with a clear dream that transcended basketball and ordinary life. Tharp and Gallimore (1976) took note of Wooden’s desire to go “beyond basketball to work with players on their personal problems and careers” (p. 9). Additionally, they included mention of his last pre-game speech: "come out of the game, win or lose, with your head high; only you and your Lord will know, but the only thing that matters is that you really mean it” (Tharp \& Gallimore, 1976, p. 21). Finally, they referred to his "Pyramid of Success”, a detailed and idealized articulation of character development (Tharp and Gallimore, 1976, p. 9; Wooden \& Jamison, 1997). All of these references suggest that Wooden's efforts, as well as the lessons he looked to instill in his players extended beyond the practice court.

Bloom (2002) suggested that "Without an explicit plan or vision from the coach, the team is unlikely to excel” (p. 452). However, very little research has examined coaches’ visions, or the role of vision in athletics. In one qualitative analysis of two baseball managers' leadership qualities and techniques, vision was explored in rare depth (Roffman, 1995). Not only was the presence of vision in the managers' leadership styles identified, but the visions were further examined, proving to share traits of "grandeur", "revolutionary goals”, and "transcendence” (Roffman, 1995, p. 90). Two additional studies pertaining to a single team building strategy that incorporates “shared vision” as its primary component, found the strategy to be effective, suggesting that vision is a necessary ingredient for developing cohesion (Voight \& Callaghan, 2001; Yukelson, 1997). Additionally, through Weinberg and McDermott's (2002) comparison of business and sports leaders' perceptions of organizational success, both groups shared the perspective that "the most common way of achieving cohesion . . . was the development of a shared vision” (p. 292). While such studies offer valuable insight into vision's potential role in athletics and its possible motivational and inspirational use, they are practically nonexistent. 
Focusing on specific coaching efforts to interact and motivate players, Vargas-Tonsing (2004; Vargas-Tonsing \& Bartholomew, 2004) conducted two studies, each suggesting that emotionally charged pre-game speeches inspire athletes and increase team efficacy. In one study, Vargas-Tonsing and Bartholomew (2004) compared three pre-recorded speeches: a control speech, a strategy-oriented speech, and an emotional speech. As mentioned, the study suggests that the emotional speech left players with increased feelings of team efficacy, but of note is the content of the speech, which includes the coach's disclosure of personal and impassioned feelings about the up-coming game, as well as his/her desire for the team to perform with confidence, pride, and a sense of destiny (Vargas-Tonsing \& Bartholomew, 2004). Similarly, in an analysis of 405 Nigerian university athletes, Adegbesan (2001) suggested that athletes are inspired and motivated by pep talks as well as messages on posters and bulletin boards. Additionally, McGowan (1988) proposed that coaches should be familiar with a variety of communication styles (e.g., directional, democratic, autocratic, etc.) in an effort to comfortably and flexibly employ varying approaches at appropriate times throughout a season. And lastly, in their chapter on coaching and effective communication, Hardy, Burke, and Crace (2005) conclude that "The most effective messages are those that reach the heart - if you can inspire emotion in the listener, a behavior change will likely occur” (p. 196).

Coaches are in a unique role to motivate other human beings, and further exploring their motivational methods may provide profound insight into general motivational practices. Few efforts have been made to further explore coaches’ tendencies to employ more traditional motivational strategies related to the individual's motives to pursue meaning, social advancement, or self-actualization through sport. However, sport would seem to be a fertile testing ground to explore such impulses and tendencies. Coaches offer a rare window into the 
life of someone committed to athletics, as well as the athletes they inspire and guide. As the leaders of the sporting world, coaches are fascinating and appropriate subjects for further analysis into traditional motivational tactics.

\section{Summary}

From posters and speeches to the overall team climate, coaches have the ability to influence their athletes in profound and meaningful ways (Adegbesan, 2001; Ames \& Archer, 1988; Cain \& Dweck, 1995; Duda, Chi, Newton, Walling, \& Catley, 1995; Nicholls, Patashnick, \& Bobbit Nolen, 1985; Vargas-Tonsing, 2004). Regarding his experiences playing and learning from John Wooden, Swen Nater sates, "It was his life that changed my life.” (Nater \& Gallimore, 2006). A seemingly profound statement for a player to make about a coach, but insightful with regard to how much impact a coach can have. As mentioned by Hardy, Burke, and Crace (2005), coaches could be considered professional motivators, paid to inspire athletes toward success. However, it would seem that there is much to be learned with regard to how expert coaches motivate, and why sport offers opportunities for coaches to make such profound impacts.

While insight and understanding is being gained with regard to how achievement goals (Cain \& Dweck, 1995; Duda \& Hall, 2001; Duda \& Nicholls, 1992; Elliott \& Dweck, 1988; Grant \& Dweck, 2003; Nicholls, Patashnick, \& Nolen, 1985) and attributions (Biddle, Hanrahan, \& Sellars, 2001; Duda \& Treasure, 2001; Eliot, 2005; Singer \& Orbach, 1999) can serve to motivate, little seems to be known about how and why athletics can motivate the types of life changing efforts that Nater references (Nater \& Gallimore, 2006). Similarly, little is understood with regard to why individuals are attracted to the medium of sport and how coaches can best manipulate that attraction to get the most out of their players. 
The theories of Frankl (1946/1984, 1969/1988), Adler (1927/1998; Ansbacher \& Ansbacher, 1956/1964; Manaster \& Corsini, 1982), and Maslow (1962, 1964/1970, 1970, 1971) offer tremendous insight into the possibility of underlying human urges that motivate action and effort. Such concepts embrace a broader notion of motivational theory that may serve to guide illuminating study in sport. Little is known about what attracts human beings to sporting opportunities, what keeps them there, and how such mediums can be used to motivate persistence, excellence, and sustained efforts. By harkening back to historical theory, new doors may be opened with regard to the motivational constructs that exist in sport, and how master coaches can motivate players to pursue athletic achievements. 


\section{References}

Ackerman, D. (1999). Deep play. New York, NY: Random House.

Adegbesan, O. A. (2001). Analysis of psyching-up techniques used with athletes in Nigerian universities. ICHPER-SD journal: The official magazine of the International Council for Health, Physical Education, Recreation, Sport, and Dance, 37(3), 50-52.

Adler, A. (1964). Superiority and social interest: A collection of later writings (H. L. Ansbacher \& R. R. Ansbacher, Eds.). Evanston, IL: Northwestern University Press.

Adler, A. (1998). Understanding life (Colin Brett, Ed.). MN: Hazelden. (Original work published 1927)

Ames, C., \& Archer, J. (1988). Achievement goals in the classroom: Students’ learning strategies and motivation processes. Journal of Educational Psychology, 80(3), 260-267.

Ansbacher, H., \& Ansbacher, R. R. (Eds.). (1964). The individual psychology of Alfred Adler: Systematic presentation in selections from his writings. New York, NY: Harper \& Row, Publishers. (Original work published 1956)

Ashby, J. S., \& Kottman, T. (1996). Inferiority as a distinction between normal and neurotic perfectionism. Individual Psychology, 52(3), 237-245.

Biddle, S. J. H., Hanrahan, S. J., \& Sellars, C. N. (2001). Attributions: Past, present, and future. In R. N. Singer, H. A. Hausenblas, \& C. M. Janelle (Eds.), Handbook of sport psychology ( $2^{\text {nd }}$ ed., pp. 444-471). New York, NY: John Wiley \& Sons, Inc.

Bloom, G. A. (2002). Coaching demands and responsibilities of expert coaches. In J. M. Silva \& D. Stevens (Eds.), Psychological Foundations of Sport (pp. 438-465). Boston, MA: Allyn and Bacon.

Bloom, G. A., Crumpton, R., \& Anderson, J. E. (1999). A systematic observation study of the teaching behaviors of an expert basketball coach. The Sport Psychologist, 13, 157-170. 
Bloom, G. A., Durand-Bush, N., \& Salmela, J. H. (1997). Pre-and postcompetition routines of expert coaches and team sports. The Sport Psychologist, 11, 127-141.

Bloom, G. A., \& Salmela, J. H. (2000). Personal characteristics of expert team sport coaches. Journal of Sport Pedagogy, 6(2), 56-76.

Bloom, G. A., Stevens, D. E., \& Wickwire, T. L. (2003). Expert coaches’ perceptions of team building. Journal of Applied Sport Psychology, 15, 129-143.

Botterill, C. (2005). Competitive drive: Embracing positive rivalries. In S. Murphy (Ed.), The sport psych handbook (pp. 37-48). Champaign, IL: Human Kinetics.

Cain, K. M., \& Dweck, C. S. (1995). The relation between motivational patterns and achievement cognitions through the elementary school years. Merrill-Palmer Quarterly, 41(1), 25-52.

Campbell, J. (2003). The hero's journey: Joseph Campbell on his life and work (Centennial Edition). Navato, CA: New World Library.

Camus, A. (1975). The plague (S. Gilbert, Trans.). New York, NY: Vintage International. (Original work published 1948)

Camus, A. (1991). The myth of Sisyphus and other essays (J. O’Brien, Trans.). New York, NY: Vintage International. (Original work published 1955)

Chang, R., \& Page, R. C. (1991). Characteristics of the self-actualized person: Visions from the East and West. Counseling and Values, 36(1), 2-10.

Chelladurai, P. (1981). Group cohesiveness, leadership and athletic performance. Canadian Association for Health, Physical Education and Recreation, 47(5), 15-21.

Chelladurai, P. (1984). Discrepancy between preferences and perceptions of leadership behavior and satisfaction of athletes in varying sports. Journal of Sport Psychology, 6, 
27-41.

Chelladurai, P. (1990). Leadership in sports: A review. International Journal of Sport Psychology, 21, 328-354.

Chelladurai, P., \& Saleh, S. D. (1978). Preferred leadership in sports. Canadian Journal of Applied Sport Sciences, 3(2), 85-92.

Chelladurai, P., \& Saleh, S. D. (1980). Dimensions of leader behavior in sports: Development of a leadership scale. Journal of Sport Psychology, 2, 34-45.

Csikszentmihalyi, M. (1990). Flow: The psychology of optimal experience. New York, NY: Harper Perennial.

Duda, J. L., Chi, L., Newton, M. L., Walling, M. D., \& Catley, D. (1995). Task and ego orientation and intrinsic motivation in sport. International Journal of Sport Psychology, 26, 40-63.

Duda, J. L., \& Hall, J. (2001). Achievement goal theory in sport: Recent extensions and future directions. In R. N. Singer, H. A. Hausenblas, \& C. M. Janelle (Eds.), Handbook of sport psychology ( $2^{\text {nd }}$ ed., pp. 417-443). New York, NY: John Wiley \& Sons, Inc.

Duda, J. L., \& Nicholls, J. G. (1992). Dimensions of achievement motivation in schoolwork and sport. Journal of Educational Psychology, 84(3), 290-299.

Duda, J. L., \& Treasure, D. C. (2001). Toward optimal motivation in sport: Fostering athletes' competence and sense of control. In J. M. Williams (Ed.), Applied sport psychology: Personal growth to peak performance (4 ${ }^{\text {th }}$ ed., pp. 43-62). Mountain View, CA: Mayfield Publishing Company.

Dweck, C. S. (1986). Motivational processes affecting learning. American Psychologist, 41(10), 1040-1048. 
Dweck, C. S. (1992). The study of goals in psychology. American Psychological Society, 3(3), 165-167.

Dweck, C. S. (2006). Mindset: The new psychology of success. New York, NY: Random House.

Eliot, J. F. (2005). Motivation: The need to achieve. In S. Murphy (Ed.), The sport psych handbook (pp. 1-18). Champaign, IL: Human Kinetics.

Elliott, E. S., \& Dweck, C. S. (1988). Goals: An approach to motivation and achievement. Journal of Personality and Social Psychology, 54(1), 5-12.

Ferguson, E. D. (2003). Social processes, personal goals, and their intertwining: Their importance in Adlerian theory practice. Journal of Individual Psychology, 59(2), 136144.

Frankl, V. E. (1984). Man’s search for meaning. New York, NY: Pocket Books. (Original work published 1946)

Frankl, V. E. (1988). The will to meaning: Foundations and applications of logotherapy, expanded edition. New York, NY: Meridian. (Original work published 1969)

Gallimore, R., \& Tharp, R. (2004). What a coach can teach a teacher, 1975-2004: Reflection and reanalysis of John Wooden's teaching practices. The Sport Psychologist, 18, 119137.

Grant, H. \& Dweck, C. S. (2003). Clarifying achievement goals and their impact. Journal of Personality and Social Psychology, 85(3), 541-553.

Griffith, B. A., \& Graham, C. C. (2004). Meeting needs and making meaning: The pursuit of goals. Journal of Individual Psychology, 60(1), 25-41.

Gundersheim, J. (1979). Self-actualization and stimulus seeking: Implications for the athlete 
and coach. Motor skills: Theory into practice, 3(2), 77-84.

Halberstam, D. (2005). The education of a coach. New York, NY: Hyperion.

Hall, M. H. (1992). The last interview of Abraham Maslow. Psychology Today, 25, 68-73.

Hamel, S., Leclerc, G., \& Lefrancois, R. (2003). A psychological outlook on the concept of transcendent actualization. The International Journal for Psychology of Religion, 13(1), 3-15.

Hardy, C. J., Burke, K. L., \& Crace, R. K. (2005). Coaching: an effective communication system. In S. Murphy (Ed.), Sport Psychology Handbook (pp. 191-212).

Heylighen, F. (1992). A cognitive-systemic reconstruction of Maslow's theory of selfactualization. Behavioral Science, 37, 39-58.

Hjertaas, T. (2004). Adler and Bnswanger: Individual psychology and existentialism. Journal of Individual Psychology, 60(4), 396-407.

Jackson, P., \& Delehanty, H. (1995). Sacred hoops: Sacred lessons of a hardwood warrior (1 $1^{\text {st }}$ Paperback ed.). New York, NY: Hyperion.

Jung, C. G. (1933). Modern man in search of a soul (W. S. Dell and C. F. Baynes, Trans.). New York, NY: Harcourt, Inc.

Jung, C. G. (2006). The undiscovered self (R. F. C. Hull, Trans.). New York, NY: Signet. (Original work published 1957)

Lazarsfeld, S. (1991). The courage for imperfection. Individual Psychology, 47(1), 93-96.

Leclerc, G., Lefrançois, R., Dubé, M., Hébert, R., \& Gaulin, P. (1998). The self-actualization concept: A content validation. Journal of Social Behavior and Personality, 13(1), 69-84. Manaster, G. J., \& Corsini, R. J., (1982). Individual psychology: Theory and practice. Itaska, IL: F. E. Peacock Publishers, Inc. 
Marx, J. (2003). Season of life. New York, NY: Simon \& Schuster.

Maslow, A. H. (1962). Toward a psychology of being. Princeton, NJ: An Insight Book, D. Van Nostrand Company, Inc.

Maslow, A. H. (1970). Religions, values, and peak-experiences. New York, NY: Penguin Compass. (Original work published 1964)

Maslow, A. H. (1970). Motivation and personality ( ${ }^{\text {nd }}$ ed.). New York, NY: Harper \& Row Publishers.

Maslow, A. H. (1971). The farther reaches of human nature. New York, NY: Penguin Compass.

McGowan, R. W. (1988). Coach/athlete communication: Group development. Journal of Applied Research in Coaching and Athletics, 3(1), 75-79.

Moore, J. W. (1970). The psychology of athletic coaching. Minneapolis, MN: Burgess Publishing Company.

Mosak, H. H., \& Dreikurs, R. (2000). Spirituality: The fifth life task. The Journal of Individual Psychology, 56(3), 257-265.

Nater, S., \& Gallimore, R. (2006). You haven't taught until they have learned. Morgantown, WV: Fitness Information Technology.

Newton, M., \& Duda, J. L. (1999). The interaction of motivational climate, dispositional goal orientations, and perceive ability in predicting indices of motivation. International Journal of Sport Psychology, 30, 63-82.

Newton, M., Duda, J. L., \& Yin, Z. (2000). Examination of the psychometric properties of the perceived motivational climate in sport questionnaire-2 in a sample of female athletes. Journal of Sports Sciences, 18, 275-290. 
Nicholls, J. G., Patashnick, M., \& Nolen, S. B. (1985). Adolescents’ theories of education. Journal of Educational Psychology, 77(6), 683-692.

Nietzsche, F. (1886). Beyond good and evil (H. Zimmern, Trans.). New York, NY: The Modern Library.

Nietzsche, F. (1969). Thus spoke Zarathustra: A book for everyone and no one (R. J. Hollingsdale, Trans.). New York, NY: Penguin Books. (Original translation published 1961; Original work published 1885)

Rascale, O., Coulomb-Cabagno, G., \& Delsarte, A. (2005). Perceived motivational climate and observed aggression as a function of competitive level in youth male French handball. Journal of Sport Behavior, 28(1), 51-67.

Roffman, P. G. (1995). A study in leadership: An analysis of the leadership styles of baseball managers and what lessons can be learned by educational leaders. Ann Arbor, MI: UMI Dissertation Services. (UMI No. 9529658)

Sartre, J. S. (1974). The age of reason (E. Sutton, Trans.). New York, NY: Vintage International. (Original work published 1947)

Segrave, J. O. (2000). Sport as escape. Journal of Sport \& Social Issues, 24(1), 61-77.

Singer, R. N., \& Orbach, I. (1999). Persistence, Excellence, and Fulfillment. In R. Lidor \& M. Bar-Eli (Eds.), Sport psychology: Linking theory and practice (pp. 167-190). Morgantown, WV: Fitness Information Technology, Inc.

Smith, R. E. (2001). Positive reinforcement, performance feedback, and performance enhancement. In J. M. Williams (Ed.), Applied sport psychology: Personal growth to peak performance ( $4^{\text {th }}$ ed., pp. 29-42). Mountain View, CA: Mayfield Publishing Company. 
Smith, S. L., Fry, M. D., Ethington, C. A., \& Li, Y. (2005). The effect of female athletes' perceptions of their coaches’ behaviors on their perceptions of the motivational climate. Journal of Applied Sport Psychology, 17, 170-177.

Tharp, R. G., \& Gallimore, R. (1976). What a coach can teach a teacher. Coaching Association of Canada Bulletin, 13, 8-10, 21.

Vallerand, R. J., \& Perreault, S. (1999). Intrinsic and extrinsic motivation in sport: Toward a hierarchical model. In R. Lidor \& M. Bar-Eli (Eds.), Sport psychology: Linking theory and practice (pp. 191-213). Morgantown, WV: Fitness Information Technology, Inc.

Vallerand, R. J., \& Rousseau, F. L. (2001). Intrinsic and extrinsic motivation in sport and exercise: A review using the hierarchical model of intrinsic and extrinsic motivation. In R. N. Singer, H. A. Hausenblas, \& C. M. Janelle (Eds.), Handbook of sport psychology ( $2^{\text {nd }}$ ed., pp. 389-416). New York, NY: John Wiley \& Sons, Inc.

Vargas-Tonsing, T. M. (2004). An examination of pre-game speeches and their effectiveness in increasing athletes’ levels of self-efficacy and emotion. Published Doctoral Thesis, Michigan State University. Eugene, OR: Kinesiology Publications, University of Oregon.

Vargas-Tonsing, T. M., \& Bartholomew, J. B. (2004). An exploratory study of the effects of pre-game speeches on team efficacy beliefs. Manuscript submitted for publication.

Voight, M., \& Callaghan, J. (2001). A team building intervention program: Application and evaluation with two university soccer teams. Journal of Sport Behavior, 24(4), 420-431.

Watts, R. E., \& Holden, J. M. (1994). Why continue to use “Fictional Finalism”? Individual Psychology, 50(2), 161-163. 
Weese, W. J. (1995). Leadership and organizational culture: An investigation of Big Ten and Mid-American Conference campus recreation administrations. Journal of Sport Management, 9, 119-134.

Weinberg, R., \& McDermott, M. (2002). A comparative analysis of sport and business organizations: Factors perceived critical for organization success. Journal of Applied Sport Psychology, 14, 282-298.

Weiss, M. R., \& Friedrichs, W. D. (1986). The influence of leader behaviors, coach attributes, and institutional variables on performance and satisfaction of collegiate basketball teams. Journal of Sport Psychology, 8, 332-346.

Williams, J. M., \& Krane, V. (2001). Psychological characteristics of peak performance. In J. M. Williams (Ed.), Applied sport psychology: Personal growth to peak performance ( $4^{\text {th }}$ ed., pp. 162-178). Mountain View, CA: Mayfield Publishing Company.

Wooden, J. R., \& Jamison, S. (1997). Wooden: A lifetime of observations and reflections on and off the court. Chicago, IL: Contemporary Books.

Yukelson, D. (1997). Principles of effective team building interventions in sport: A direct services approach at Penn State University. Journal of Applied Sport Psychology, 9, 7396. 
Motivation 83

Appendix G

A Qualitative Analysis of Motivational Strategies Employed by Elite Lacrosse Coaches 
Running head: MOTIVATION

\section{Motivation:}

A Qualitative Analysis of Motivational Strategies Employed

by Elite Lacrosse Coaches

Dan Leidl, MA,

Joe Frontiera, MS, \&

James Siestreem

West Virginia University

April, 2008

21 McKinley Street

Westover, WV 26501

516-297-2466

Daniel.Leidl@mail.wvu.edu 


\begin{abstract}
While motivation has long been a topic of intrigue in coaching and sport, it has been subject to little qualitative analysis. Coaches are often regarded as motivators by trade (Hardy, Burke, \& Crace, 2005), and there is seemingly a tremendous amount to learn from such expert practitioners. In talking with coaches about how they motivate one may gain further insight regarding the successful mechanisms they rely on. Through this study, six elite lacrosse coaches were interviewed regarding their motivational tactics. In these interviews the coaches provided like-minded responses that were categorized and further discussed herein. Such information could provide the foundation for further inquiry into the motivational efforts of expert coaches, affording a better understanding of successful motivational tactics.
\end{abstract}




\section{Motivation: A Qualitative Analysis of Motivational Strategies Employed by Elite Lacrosse Coaches}

“The essence of coaching comes down to teaching and motivating”

(Hardy, Burke, \& Crace, 2005, p. 191)

\section{Introduction}

Hardy, Burke, and Crace (2005) do not mince words in defining the essence of coaching. While much can be said of what is taught and how one motivates, the notion that there is little more to coaching than teaching and motivating would seem to ring true. Regardless of one's formal definition of coaching, little debate can be made to argue against the notion that much of coaching can be reduced to motivation. In addressing this specific subject, let us further consider what is known of motivational strategies in coaching, how coaches actively motivate their athletes, and what previous research may not be addressing with regard to motivation in sport.

Much has been researched and written on motivation in sport, yet little effort has been made to qualitatively assess how accomplished coaches motivate their athletes. Little attention has been paid to cataloging specific motivational interventions, coaches' efforts to play off of their athletes’ natural impulses to seek achievement, and tying sport into the more global motives that have been theorized to guide human efforts of all kinds. In working to further understand these issues, let us briefly review some motivational constructs that are often associated with sport, some more global constructs that are rarely included in the research pertaining to sport, and how coaches have been previously assessed with regard to their motivational efforts.

\section{Team Climate}

Motivation is a vast and complex topic, and a coach's capacity to influence his/her players can be viewed in a variety of perspectives. From the words they use in practice to the 
overall vision that guides them, coaches are afforded a variety of opportunities to impact the players and teams they lead. The general team climate that a coach develops serves as a profound and influential incubator in which athletes will flourish or falter (Ames \& Archer, 1988; Cain \& Dweck, 1995; Duda, Chi, Newton, Walling, \& Catley, 1995; Nicholls, Patashnick, \& Bobbit Nolen, 1985). Climates that foster a focus on overcoming goals through a sincere and dogged work ethic, the fun in playing a sport, persistence, and patience (i.e., task oriented) seem to also foster individual enjoyment, interest, and increased effort (Newton \& Duda, 1999; Newton, Duda, \& Yin, 2000). In contrast, team climates that emphasize the importance of winning over the journey, punish poor outcomes as opposed to celebrating hard work, and commend natural ability over continued effort (i.e., ego oriented) seem to leave athletes feeling pressured, anxious, and unenthusiastic (Newton \& Duda, 1999; Newton, Duda, \& Yin, 2000).

Coaches play a significant role in developing these climates, and motivating corresponding attitudes and behaviors. In accordance with their research on climate, Smith, Fry, Ethington, and Li (2005) concluded that “athletes’ perceptions of their coaches’ behaviors contribute significantly to their perceptions of the climate” (p. 176). In fact, it has been suggested that the team climate a coach develops can even impact the level of aggression among his/her players (Rascale, Coulomb-Cabagno, \& Delsarte, 2005). Coaches who scold more while emphasizing victory and innate ability are more likely to develop climates that seem to promote more aggressive playing styles (Rascale et al., 2005).

\section{What Coaches Say}

While the climate a coach develops can motivate and impact a team of athletes, what do coaches say and do to develop such climates? How are coaches talking to athletes in practices, and how are athletes motivated by specific tactics? In one of the most memorable studies related 
to coaching, Tharp and Gallimore (1976) observed the great John Wooden coach his UCLA team throughout fifteen basketball practices. The Wooden study focused on capturing the tactics and techniques of a master coach at work, and organized all of Wooden’s audible utterances into eleven categories (Gallimore \& Tharp, 2004; Tharp \& Gallimore, 1976). In coaching his team Wooden was found to have used Instructions 50.3\% of the time, while the next highest category proved to be Hustles, which only occurred $12 \%$ of the time (Gallimore \& Tharp, 2004; Tharp \& Gallimore, 1976). As per the manner in which Tharp and Gallimore (1976) coded the data, Wooden was never observed engaging in pep talks or traditional motivational speeches, and was rarely seen scolding or praising his players. However, it should be reemphasized that the study was only conducted throughout a series of practices, $6.6 \%$ was unseen or heard, and the research was never extended to the locker room, office, bus, or game day (Gallimore \& Tharp, 2004; Tharp \& Gallimore, 1976).

While much of the Wooden study focused on the manner in which Wooden taught his players, Tharp and Gallimore’s (1976; Gallimore \& Tharp, 2004) work also provides insight into Wooden's efforts to inspire and motivate his players through methods that transcend the world of basketball. Tharp and Gallimore (1976) took note of Wooden’s desire to go "beyond basketball to work with players on their personal problems and careers” (p. 9). They also included mention of his last pre-game speech: “come out of the game, win or lose, with your head high; only you and your Lord will know, but the only thing that matters is that you really mean it” (Tharp \& Gallimore, 1976, p. 21). Additionally, Tharp and Gallimore (1976) make reference to Wooden’s well known articulation of one’s journey toward success: the "Pyramid of Success” (p. 9). The "Pyramid of Success" is a broad conceptualization of how an individual and team can work toward the achievement of their goals, and extends far beyond Instructions and Hustles (Wooden 
\& Jamison, 1997). The "Pyramid" is a construction of character traits that would seem to motivate athletic efforts in ways that tactical and technical instruction could not, and includes categories like Team Spirit, Faith, Confidence, and Competitive Greatness (Wooden \& Jamison, 1997). All of these references suggest that Wooden's tactics as well as the lessons he looked to instill in his players may have extended beyond the practice court, which leaves one wondering if Wooden's motivational efforts and impact extended far beyond those captured in Tharp and Gallimore’s (1976; Gallimore \& Tharp, 2004) work.

In a similar study conducted with basketball coach Jerry Tarkanian, Bloom, Crumpton, and Anderson (1999) found that Tactical (29\%) and Technical (13.9\%) Instructions, coupled with Hustles (16\%) represented more than 50\% of statements recorded during ten practices observed throughout a season. As per the findings, Tarkanian was seemingly methodical in sticking to tactical and technical instructions related to the game of basketball, and used words of encouragement when practice efforts were presumably less inspiring. While the frequency a master coach relies on instructive words is intriguing, the study employed a method that relied on coding data in accordance with a twelve-item coding-sheet that was developed prior to the study and excluded categories related to more emotional talks or inspiring words (Bloom, Crumpton, \& Anderson, 1999). The coding sheet included categories such as Praise/encouragement (13.6\%), Scolds (6\%), and Humor (1\%), yet no examples of the utterances that were grouped into the categories were included in the study, as Tarkanian's actual words were not incorporated into the write-up (Bloom, Crumpton, \& Anderson, 1999). Similar to the Wooden study, there were no efforts made to better understand how a coach relates to his players in the locker room after practice, in the huddle before a game, in the office, through letters and phone calls, or in the travel buses and hotel halls. 
Vision

While the Tarkanian study (Bloom, Crumpton, \& Anderson, 1999) may fail to offer insight into a coach’s ability to impact players through a vision or more idealized goals, Bloom (2002) also suggested that "Without an explicit plan or vision from the coach, the team is unlikely to excel” (p. 452). Perhaps the importance and potential impact of a coach's vision is simply too apparent to warrant extensive review, but very little research has examined coaches’ visions or the role of vision in athletics.

In one qualitative analysis of two baseball managers, vision was explored in rare depth (Roffman, 1995). Not only was the presence of vision in the managers’ leadership styles identified, but their visions were explored, discussed, and examined, proving to share traits of “grandeur”, “revolutionary goals”, and “transcendence” (Roffman, 1995, p. 90). Two additional studies of a specific team building strategy suggested that shared vision among team members is an integral component of team cohesion and unity (Voight \& Callaghan, 2001; Yukelson, 1997). Additionally, through Weinberg and McDermott's (2002) comparison of business and sports leaders' perceptions of organizational success, both groups shared the perspective that "the most common way of achieving cohesion ... was the development of a shared vision” (p. 292). While such studies offer valuable insight into vision's potential role in athletics and its possible motivational and inspirational use, they are sparse.

\section{Goals}

Although somewhat of a divergence from vision, many more studies have explored the role of goals in sport. It has been widely reported that goals may work to motivate a number of variables ranging from team cohesion to enhanced individual effort (Carron, Hausenblas, \& Eys, 2005). Although not focused on the field of sport, Lock and Latham (2002) have suggested that 
goals influence a number of factors including the direction of effort, persistence, and energy. While Locke and Latham’s (2002; 2006; Locke, Shaw, Saari, \& Latham, 1981) work has been more general, several studies have worked to confirm their findings in a context specific to physical activity and performance, suggesting that different types of goals (e.g., long- vs. shortterm goals, realistic vs. unrealistic goals, and challenging verse simplistic goals) produce varying motivational effects (Bar-Eli, Hartman, \& Levy-Kolker, 1994; Bar-Eli, M., Tenenbaum, G., Pie, J. S., Btesh, Y., \& Almog, A., 1997). Similarly, one recent research article indicates that goals associated with the fulfillment of basic psychological needs (e.g., autonomy and competence) are positively associated with goal attainment (Smith, Ntoumanis, \& Duda, 2007). These findings also suggested that the completion of goals predicted psychological well-being or general life satisfaction (Smith, Ntoumanis, \& Duda, 2007). In addition to the influence goals may have on the individual, they may also positively affect the team, as team goal setting exercises have been found to favorably impact the sustainability (Senecal, Loughead, \& Bloom, 2008) and development of team cohesion (Yukelson, 1997).

The Pre-Game Speech

Unlike the literature related to goals, but similar to the paucity of research that has focused on vision, little seems to be known about how motivational techniques are employed by coaches and how they impact players. Little research has focused on examining specific motivational efforts coaches employ, and those classically popularized by analysts and movies (i.e., pre-game speeches, stories, etc.) seem largely ignored. Vargas-Tonsing (2004; VargasTonsing \& Bartholomew, 2004) conducted two studies focused on pre-game speeches and found that pre-game speeches inspire and increase team efficacy. In one study, Vargas-Tonsing and Bartholomew (2004) compared three pre-recorded speeches: a control speech, a strategy-oriented 
speech, and an emotional speech, and found that the emotional speech left players with increased feelings of team efficacy. Additionally, the content of the speech is of particular note, as it included the coach's disclosure of personal and impassioned feelings about the up-coming game, as well as his/her desire for the team to perform with confidence, pride, and a sense of destiny (Vargas-Tonsing \& Bartholomew, 2004).

Although more general in nature, in an analysis of 405 Nigerian university athletes, Adegbesan (2001) suggested that athletes are inspired and motivated by pep talks as well as messages on posters and bulletin boards. Additionally, McGowan (1988) proposed that coaches should be familiar with a variety of communication styles (e.g., directional, democratic, autocratic, etc.) in an effort to comfortably and flexibly employ varying approaches at appropriate times throughout a season. While McGowan’s (1988) findings are focused on communication styles, one can not help but wonder if coaches would benefit their efforts by employing a variety of references and mediums when working to motivate their players. For example, would a coach more aptly motivate his/her athletes with the combined use of speeches, quotes, music, film, photographs, program history, school expectations, etc.? While little is known about how to best inspire athletes, Hardy, Burke, and Crace (2005) conclude that "The most effective messages are those that reach the heart - if you can inspire emotion in the listener, a behavior change will likely occur” (p. 196).

\section{Conclusion}

While the literature regarding coaches and specific motivational strategies seems scant, there is significant reason for further exploring coaches' efforts to motivate. Coaches serve a unique role as professional motivators, and little seems to be understood about the motivational 
methods they employ. In addressing such a concern, it would seem appropriate to sit down with several highly accomplished coaches and discuss motivational efforts and rationale.

\section{Methodology}

A criterion sample was defined, and an extreme case, purposive sample of convenience was used (Patton, 2002). Elite men's lacrosse coaches $(N=6)$, all of whom have coached with an international team were interviewed. The sample criteria limited the study to men's coaches who have coached with a national team (i.e., Ireland, Italy, or USA) that competed in the World Lacrosse Championships, as such a distinction is widely considered a pinnacle achievement in the world of lacrosse coaching. While coaching an international team is a fine distinction, it is generally recognized as a temporary assignment, and hardly represents the complete body of a coach's work. In addition to their international coaching experiences, the sample represented coaches with various professional experiences and distinctions (i.e., NCAA Tournament and Championship Experience, State Championship and Tournament Experience, etc.). Participants were specifically asked to respond in accordance to their career coaching, and accordingly, drew on their experiences coaching college and high school lacrosse to answer each question.

Semi-structured interviews were conducted with the identified coaches, and each interview proved to be more of a conversational discourse between the coach and the primary investigator. Interviews were recorded for accuracy, and averaged one hour in length. Interviews were based on a series of questions designed by the primary investigator and intended to explore practices and beliefs associated with team culture and motivation. The initial series of questions were reviewed and critiqued by a licensed psychologist and faculty member who has an extensive background in social and sport psychology. Additionally, months prior to the formal interviews, an elite Division III lacrosse coach who did not have international coaching 
experience volunteered to practice the interview and further discuss the effectiveness of the questions. The final interview outline contains five questions, of which the final three focus exclusively on motivation. The focus of this paper is on the responses to the final three questions, which pertain to motivational strategies and beliefs.

After the completion of the six interviews, the recordings were fully transcribed to facilitate further analysis. The researchers independently reviewed transcriptions, and developed coding categories associated with responses pertaining to the following three questions:

1. How do you establish and discuss goals/vision with your team? And describe some from years past?

2. How do you motivate your team, and what do you generally motivate them to do (e.g., win, maintain confidence, execute, get good grades, be good people, etc.)?

3. What types of stories do you share with your team throughout a season, and what are there purpose (e.g., stories about historic players, stories about teams from the past, personal anecdotes, etc.)?

Following the development of individual codes, the researchers convened to develop a consensus regarding response categories that best described coaches’ collective understandings and insight into motivational strategies and beliefs.

\section{Results}

All coaches interviewed expressed a palpable passion for their sport, job, and the charge of motivating young athletes. Participants shared numerous stories and tactics with regard to motivation, and seemed fully invested in their efforts to inspire their teams. In response to the interviews and data collected, three general themes representing the varying brands of motivational effort expressed by the participants were developed: Personal Responsibility, Tools, 
and Transcendence. The names of these themes and the categories that comprise them were developed by the researchers, and are intended to adequately represent the data they reflect.

Of note was the relative consistency with which participants spoke about motivational tactics and approaches. There proved to be considerable overlap between the methods each coach used, and there also appeared to be a similar degree of commitment by each coach to the three categories identified. In other words, the individual coaches seemed to share some degree of commitment to each of the three categories captured. When this phenomenon was considered a model representing the coaches' efforts to motivate their athletes seemed to naturally emerge.

\section{Personal Responsibility}

In working to identify and categorize the tactics that the coaches used to motivate their athletes, it initially became apparent that the coaches took tremendous responsibility on themselves. The participants took ownership for personal actions that they believed to be inherently motivating for young athletes to perceive. As leaders, the coaches spoke of personal expectations that were later grouped into three general categories that pertained to their responsibilities to their athletes and team: Interpersonal Growth, Personal Attitude, and Respect for Individuality. These categories were housed beneath the theme of Personal Responsibility, as they have been identified as efforts unique to the coach that are intended to assist with the general motivation of the athletes they are leading.

Interpersonal Growth pertains to a coach’s willingness to grow, develop, change, and advance. Two coaches in particular identified this category as a critical component to their continued success. As discussed by these coaches, their efforts to maintain a degree of flexibility and open mindedness allowed for beneficial advancements throughout their careers. One coach reflected on his early efforts to motivate, and his openness to changing for the benefit of his 
players. He recalled that "I used to be the motivating guy that would have to do everything but stand on my head in the locker room the night before a game and the day of a game to really get the guys fired up. I don't do much of that anymore. . .[now] I just talk to guys.” Similarly, the coach with the most experience and achievements (several Division I National Championships and numerous league titles) quite simply stated that "you have to keep up with the times. ..” In short, these coaches saw a value in staying current and flexible, and saw a motivating quality in presenting themselves as such.

All of the coaches interviewed shared the perspective that their Personal Attitude harbored tremendous motivational force. They identified various traits and behaviors that they expected of themselves, and hoped to see reflected in their athletes. From diligence and persistence to honesty, selflessness and humor, coaches suggested that their efforts to project consistent character traits would prove inherently motivating to their athletes. Regarding his own brand of integrity as well as expectations for his players, one coach stated, "If I'm asking them to do something then I had better be able to deliver the same thing back. Kids are smart. If you're a phony, they're gonna see right through ya, real quick.” To this end, coaches believed that they could model and inspire traits that would prove motivating as well as beneficial to their players' success. Another coach spoke of the importance of care in his program, and that his priorities pertained to being honest, open, and seeing his athletes graduate from school: "We use the ethic of caring. We care about them. ..We don't guarantee them playing time, but we do everything we can to see that they graduate.” In this regard, coaches found honesty and consistency integral in relating to and motivating productivity. Coaches also mentioned the importance of staying positive regardless of the score or win/loss record, one coach succinctly said, “I don’t dwell on the negative”, while another stated, "If you do something good today than 
just grow with it”. These coaches had specific ideals of what they wanted to project and how they could do it. They found these efforts to be consistent with motivating their teams, but took it upon themselves to model and exhibit the traits that personally resonated with them.

Coaches also expressed a sincere regard for the individual process related to motivation. One coach built this construct into his team's pre-game warm-up, affording players the time and space to do what they need to do as individuals to mentally prepare. Regarding the choice to incorporate an individually focused pre-game routine, the coach stated that "a lot of guys love it. It just says go do your thing, get yourself ready . . . whether you're a rah-rah guy or a quiet guy, whether you listen to music or read a book, whether you need to use the men's room or you just want to close your eyes for a couple of minutes.” Additionally, other coaches reflected the importance of honoring their athlete’s individual goals and shaping expectations accordingly. One coach stated that “we're talking about matching their level of commitment, their level of play to their personality and whatever their personal goals are.” In this regard, coaches seemed committed to each player's personal journey. Coaches also proved to be in-tune with the amount of self motivation their athletes should or could have, as they had a keen awareness and expectation regarding self motivation among their players. Coaches seemed consistent in their perspective that athletes interested in achieving had to bring a certain level of motivation and desire. Although the athletes may need to be somewhat self motivated, it was the coaches who were responsible for taking the leap of faith that “people should be self motivated” and continued with their efforts undeterred. In this sense, coaches met the athletes where they were, expecting a degree of enthusiasm, but working to maintain and/or enhance motivation among the team when necessary. 
Throughout the interviews, coaches seemed to take on a great deal of responsibility for how they carry themselves and interact with their athletes. They projected a standard of expectation for themselves, and seemed to implicitly challenge their athletes to match their effort, integrity, and passion for the team. These coaches seemed committed to personal growth and specific traits, while also presenting a degree of openness to the individuality and internal drive among their players. The coaches seemed to develop a motivational foundation for their athletes within themselves, and then extended themselves accordingly through additional motivational methods.

Tools

In their efforts to motivate, the participants certainly did not stop with themselves. They drew on a number of motivational tactics to further prod and coax their athletes toward heightened levels of success. In assessing the data, four specific categories related to this concept emerged: Goal Setting, Rewards, Punishment/Accountability, and Environment. These Tools were used to further instigate effort among the athletes and teams the participants coached, and were frequently present and discussed throughout the interviews.

Goal Setting proved to be a consistent item in all of the participants' motivational repertoires. Although coaches used varying goal setting strategies, they all seemed to employ some degree of goal setting into their programs. Interestingly, the variance regarding goal setting efforts and exercises was notable, as coaches all seemed to impress their own brand of goal setting on their teams. Coaches mentioned short and long term goals, academic and sport goals, goals specific to the varying positions on the field, the development and monitoring of goal charts for each game, and the difference between personal and team goals. One coach who worked to impress the importance of team over individual goals commented, "I tend to not be 
one of those guys who want to see a kid break down his individual goals cause that sets his mind that individual goals are very, very important.” Regardless of how goals are implemented or what they pertained to, the coaches seemed to agree that there was a place for goals in the context of their team's efforts. In summarizing the impact goal setting seemed to have on each coach’s programs, perhaps the most eloquent portrayal of goal setting was expressed nearly verbatim by two coaches: “to get a little better, that’s our basic goal. Something, in some way, make yourself a little better", and "there should be a goal every day, and every day one of your goals should be: You're a better team than you were the day before.”

Rewards were also mentioned with some degree of consistency between each of the coaches. While the rewards mentioned ranged from larger life rewards such as graduation and job preparation to more tangible prizes, coaches seemed cognizant of the value and motivational impact rewards could have on their athletes. Two coaches spoke of token rewards that were handed out to valuable players after wins or exceptional performances. While these rewards may have been as minor as a sticker or a poster, they took on considerable value within the context of the team and were regarded as something to strive for. As one coach mentioned with regard to such seemingly trivial rewards, “That's important to them.” Such rewards represent effort and excellence within the team construct and recognize the few individuals who embody the team's values in times of success. While not as concrete, coaches also spoke of the rewards of education, pride, and accomplishment for players who stick with a program and give of themselves. As one coach articulated, even players who do not play have incentives for staying with the team, as “it's still exciting to be a part of, it's still prestigious to be a part of, it's still going to help you in your future”. 
As with Rewards, Punishment/Accountability was also seen as a significant motivating force. Coaches spoke of cutting players who were unwilling to meet team expectations on and off the field. They mentioned putting teams on the end line and having them run sprints during lackluster practices. Similarly, they talked about sitting players who were not performing or listening, and of not going out of their way to recommend players to college programs and/or jobs if they were not reliable during their tenor as a player. One coach spoke of a hypothetical example in which a player was not performing in class and was not completing assignments. He said, "If I'm aware of that, I can either sit the kid out at game time or have the kid run some sprints. There's accountability in the program, and that's a big, big part of making kids responsible”. In this regard there was not only a punishment, but there was an identified reason and purpose. The coaches wanted to push their players to be better in a variety of facets of their lives, and were willing to punish them with sprints, playing time, or even cutting them if the greater good could be served. Finally, as one coach emphasized, “It could be the best kid, if he’s a jerk, he’s gone. A lot of people will say that, but we do it, and I mean Division I First-Team All Americans tossed.” The coach went on to relay a specific anecdote in which two exceptional high school players were drinking alcohol and subsequently dismissed from the team. The team suffered, losing a championship because of their star players absences, but the individuals learned valuable lessons and went on to graduate college and have celebrated collegiate careers. In the end the coach affirmed, "But I would do it again. . .I think it’s the right thing to do.” Environment proved to be an intriguing category, as the participants noted a variety of external factors that they manipulated with the intention of motivating their teams. Although the Environment may extend beyond the control of the coaches, they used specific elements to motivate and excite their teams. The coaches seemed to manipulate certain factors within the 
environment to increase motivation, while articulating factors that were out of their control in ways that seemingly proved motivating to the athletes they worked with. For example, two coaches spoke of the motivational impact of internal competition with one coach stating, “you want that healthy competition, that healthy competitiveness on your team because it motivates the kids everyday. It pushes them.” While something like internal competition can be fostered from the coach, other elements, like the school and the league are well beyond the coaches' control. However, the participants spoke of how they emphasized the value and motivational influence of playing for an Ivy League school, for a service academy, or in an elite conference. The participants drew on the history and prestige of their environment to further motivate and drive their players.

With the use of these tools, coaches worked to motivate and inspire in a variety of methods. Coaches utilized the motivational power of Goals, as well as the tools of Rewards and Punishments/Accountability so as to drive their teams toward considerable success. While no one element would seem more beneficial than another, coaches drew on a number of techniques to inspire and advance their players, fostering growth and continued effort.

\section{Transcendence}

Perhaps the most difficult theme to label, Transcendence seemed to be a somewhat ethereal concept that related to motivational strategies that were associated with something that extended beyond the team, something meaningful beyond lacrosse, something that transcended the game. The participants all spoke of the importance of perceiving the game as something bigger than it is, and told numerous stories of life lessons related to practice, playing at one’s best, and individuals who typify an inspiring mindset. In this sense, the participants seemed to motivate their athletes by emphasizing the value of effort and determination in a context that 
extended beyond sport. To further define this theme, two categories were developed: Life Lessons and Legacy.

The coaches spoke of the legacy their athletes had the opportunity and potential to leave, as well as the legacy that they were associated with. The Legacy piece seemed to motivate in two ways. Not only did players have an opportunity to leave a legacy, they also had an opportunity to further contribute and/or be a part of an established legacy. One coach explained an exercise he developed for his team, in which players researched those who wore their jersey before them. He spoke of the value related to connecting present players to the players of the past, and stated, "I try to give them a bigger picture than just their immediate one year or four years, depending on how they're looking at it, and letting them know that they are in something that is really, really cool.” While this coach worked to motivate current players by connecting them to their historic counterparts, other coaches spoke of their efforts to remind players that they too can give back and leave their mark. One coach spoke of the importance of developing leaders and emphasized the value of encouraging older players to extend themselves to younger players, stating, “A freshman is paired up with a senior, and the senior is responsible for helping him get through his freshman year and reports back to me if there are any big issues going on.” In this system the seniors are encouraged to develop leadership skills while also being encouraged to leave their impression on the program by assisting and guiding the future.

The participants also spoke of perceiving a season as a metaphor for life, hitting challenges head on and working to overcome them in respectable and righteous terms. They emphasized the opportunity to impart Life Lessons on their players, and seemed to perceive the lacrosse experience as a microcosm for life at large. As one coach stated, “there's always some crisis every year, and how you deal with that crisis has a lot to do with how your season goes.” 
To these coaches a season was more than a series of practices and games, it was an opportunity to prepare young men for the larger challenges of life. One coach recalled an accident in which a player died in pre-game warm-ups, stating that "we just remind guys that it is a game, and that they are playing and representing [their institution]”. To this coach, life experiences are humbling and valuable in assisting players to maintain perspective regarding what they do, why they do it, and who they are representing. An additional coach spoke of the urgency that tends to accompany life, and the notion that one should not wait to pursue their goals and make an impact. In urging players to contribute their best now, the coach passionately stated, “one of my big things. . .is every day that you piss away an opportunity, you can never have that opportunity again.” To this end, these coaches wanted to impart upon their players that wasted time could translate into wasted opportunity. In the spirit of this sentiment, lacrosse seems to be an opportunity for these coaches to teach and assist their players to grow in ways that extend far beyond the field of play.

Although this notion of motivating through transcendent means through Legacy and Life Lessons may be difficult to convey, the participants frequently addressed these points in the context of stories. The coaches spoke about players who stayed connected with their programs in effort to emphasize the individual legacy one player can have. They spoke of previous seasons in which lessons were learned, or specific individuals who were particularly inspiring. They mentioned daily messages that they worked to convey at practice, and the value of allowing student-athletes to define their own experiences and develop their own stories. They shared personal stories of overcoming adversity, and how they related their personal struggles to the struggles of their individual players and teams. While Transcendence may have proved difficult to define as a clear and succinct motivational category, its impact and power seems poignant and 
genuine. These coaches saw lacrosse as a teaching tool, and worked to motivate by reminding athletes that there was more to life than the game, and the game could teach them more about life. In summarizing the perceived power of lacrosse as a teacher, one coach stated, "for the most part the people who are in lacrosse are supportive people, positive people, and successful people. It's a fraternity, and it's different than any other sport. It's a special sport with special people, and that's what I try to reinforce with my kids.” 
Model

In assessing the responses of the coaches who participated in this study, there proved to be tremendous overlap between the methods of one coach and another. To follow is a model that represents the manner in which the three main motivational themes may be employed to equally and synchronously motivate athletes and teams.

Figure 1. Motivation model.

\section{Transcendence}

- Life Lessons

- Legacy

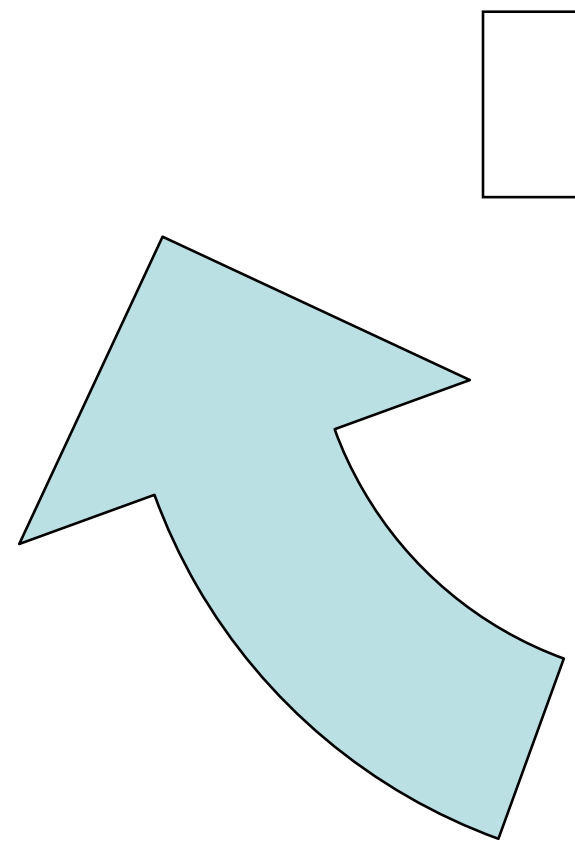

\section{Motivation}

\section{Tools}

- Goal Setting

- Rewards

- Punishment/ Accountability

- Environment

\section{Personal}

Responsibility

- Interpersonal

Growth

- Personal Attitude

- Respect for Individuality

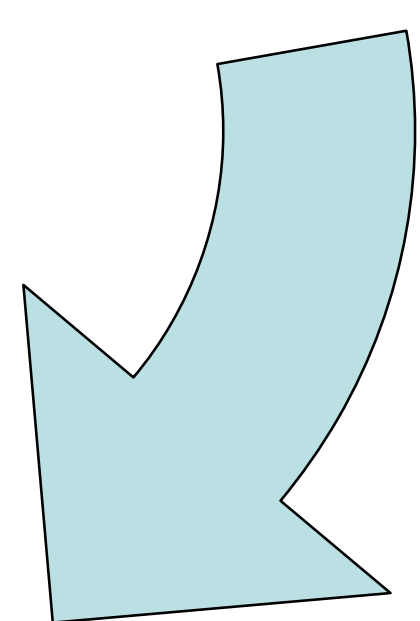




\section{Discussion \& Future Implications}

This research was intended to explore the methods coaches employ when working to motivate their teams and athletes. It focused on six male coaches who have all reached the international ranks of coaching while also maintaining prestigious professional coaching careers in men's lacrosse. A number of motivational strategies were highlighted and identified, all of which shed significant light on a subject that little exploration has been focused on. It was noted by all investigators that the coaches displayed zeal and passion for the subject matter, discussing their motivational efforts with a candor and detail that was expressive of considerable thought, planning, and experience. Additionally, the opportunity to speak with these coaches through a qualitative design afforded a rich data set that will ideally inspire future research efforts.

In addressing some setbacks to this study, the small and homogenous sample size should be accommodated for in future work. Including female coaches, coaches from other sports, and perhaps limiting coaches to the same professional background (e.g., Collegiate Coaches, Division I Coaches, etc.) could prove beneficial. For example, interviews with professional football coaches may yield a dramatically different data set than the one collected. Regardless, the data collected did produce significant insight into motivational methods that may exist far beyond the coaches and programs investigated through this study.

The data collected seemed to establish a genuine and supportive foundation for future research, as a variety of questions and concerns need to be addressed. Little is known about the nature and consistency of many of the motivational methods discussed, and there may prove to be ample opportunity for future investigation regarding additional sports, female coaches, and cultural variations to motivating athletes. Additionally, how are such motivational efforts expressed throughout a season? Are they employed daily, through locker room photos and 
posters, through media interviews, pre-season exercises, etc? How do such methods impact motivational constructs readily researched and written about (i.e., Motivational Climate, Achievement Goals, Intrinsic/Extrinsic Motivation, etc.)? How do such methods work, and how influential is one method over another? Can players be truly motivated by a coach’s individual growth, or a consistent series of rewards, and do these techniques yield differing results? Finally, is there a universality to such motivational methods? Do certain methods impact athletes on a global level, which ones are most effective, and could/are such methods employed in non-sporting disciplines?

\section{Summary}

In listening to elite coaches talk about the motivational methods they use to inspire and motivate their athletes proved to be an enlightening and eye-opening exercise. There would seem to be a rich storehouse of methods and tactics that are currently being employed by coaching practitioners that little is known about. While much has been written and researched about motivation in the sporting context, there is still much to be explained and discovered. Coaches have a unique insight into this material, yet few studies have afforded them the opportunity to share their experiences and ideas. Beyond the data collected or any value its analysis may have, the opportunity to share the words and practices of skilled coaches was a wonderful and humbling experience that will ideally inspire others to partake in similar study and exploration. 


\section{References}

Adegbesan, O. A. (2001). Analysis of psyching-up techniques used with athletes in Nigerian universities. ICHPER-SD journal: The official magazine of the International Council for Health, Physical Education, Recreation, Sport, and Dance, 37(3), 50-52.

Ames, C., \& Archer, J. (1988). Achievement goals in the classroom: Students’ learning strategies and motivation processes. Journal of Educational Psychology, 80(3), 260-267.

Bar-Eli, M., Hartman, I., \& Levy-Kolker, N. (1994). Using goal setting to improve physical performance of adolescents with behavior disorders: The effect of goal proximity. Adapted Physical Activity Quarterly, 11(1), 86-88.

Bar-Eli, M., Tenenbaum, G., Pie, J. S., Btesh, Y., \& Almog, A. (1997). Effect of goal difficulty, goal specificity and duration of practice time intervals on muscular endurance performance. Journal of Sports Sciences, 15, 125-135.

Bloom, G. A., Crumpton, R., \& Anderson, J. E. (1999). A systematic observation study of the teaching behaviors of an expert basketball coach. The Sport Psychologist, 13, 157-170.

Bloom, G. A. (2002). Coaching demands and responsibilities of expert coaches. In J. M. Silva \& D. Stevens (Eds.), Psychological Foundations of Sport (pp. 438-465). Boston, MA: Allyn and Bacon.

Cain, K. M., \& Dweck, C. S. (1995). The relation between motivational patterns and achievement cognitions through the elementary school years. Merrill-Palmer Quarterly, 41(1), 25-52.

Carron, A. V., Hausenblas, H. A., \& Eys, M. A. (2005). Group dynamics in sport (3 ${ }^{\text {rd }}$ ed.). Morgantown, WV: Fitness Information Technology.

Duda, J. L., Chi, L., Newton, M. L., Walling, M. D., \& Catley, D. (1995). Task and ego 
orientation and intrinsic motivation in sport. International Journal of Sport Psychology, 26, 40-63.

Gallimore, R., \& Tharp, R. (2004). What a coach can teach a teacher, 1975-2004: Reflection and reanalysis of John Wooden’s teaching practices. The Sport Psychologist, 18, 119137.

Hardy, C. J., Burke, K. L., \& Crace, R. K. (2005). Coaching: an effective communication system. In S. Murphy (Ed.), Sport Psychology Handbook (pp. 191-212).

Lock, E. A., \& Latham, G. P. (2006). New directions in goal-setting theory. Current Directions in Psychological Science, 15(5), 265-268.

Lock, E. A., \& Latham, G. P. (2002). Building a practically useful theory of goal setting and task motivation: A 35-year odyssey. American Psychologist, 57(9), 705-717.

Locke, E. A., Shaw, K. N., Saari, L. M., \& Latham, G. P. (1981). Goal setting and task performance: 1969-1980. Psychological Bulletin, 90(1), 125-152.

McGowan, R. W. (1988). Coach/athlete communication: Group development. Journal of Applied Research in Coaching and Athletics, 3(1), 75-79.

Newton, M., \& Duda, J. L. (1999). The interaction of motivational climate, dispositional goal orientations, and perceived ability in predicting indices of motivation. International Journal of Sport Psychology, 30, 63-82.

Newton, M., Duda, J. L., \& Yin, Z. (2000). Examination of the psychometric properties of the Perceived Motivational Climate in Sports Questionnaire-2 in sample of female athletes. Journal of Sports in Science, 18, 275-290.

Nicholls, J. G., Patashnick, M., \& Bobbit Nolen, S. (1985). Adolescents’ theories of education. Journal of Educational Psychology, 77(6), 683-691. 
Roffman, P. G. (1995). A study in leadership: An analysis of the leadership styles of baseball managers and what lessons can be learned by educational leaders. Ann Arbor, MI: UMI Dissertation Services. (UMI No. 9529658)

Rascale, O., Coulomb-Cabagno, G., \& Delsarte, A. (2005). Perceived motivational climate and observed aggression as a function of competitive level in youth male French handball. Journal of Sport Behavior, 28(1), 51-67.

Senecal, J. Loughead, T. M., \& Bloom, G. A. (2008). A season-long team-building intervention: Examining the effect of team goal setting on cohesion. Journal of Sport \& Exercise Psychology, 30, 186-199.

Smith, S. L., Fry, M. D., Ethington, C. A., \& Li, Y. (2005). The effect of female athletes' perceptions of their coaches' behaviors on their perceptions of the motivational climate. Journal of Applied Sport Psychology, 17, 170-177.

Smith, A., Ntoumanis, N., \& Duda, J. (2007). Goal striving, goal attainment, and well-being: Adapting and testing the self-concordance model in sport. Journal of Sport \& Exercise Psychology, 29, 763-782.

Tharp, R. G., \& Gallimore, R. (1976). What a coach can teach a teacher. Coaching Association of Canada Bulletin, 13, 8-10, 21.

Vargas-Tonsing, T. M. (2004). An examination of pre-game speeches and their effectiveness in increasing athletes' levels of self-efficacy and emotion. Published Doctoral Thesis, Michigan State University. Eugene, OR: Kinesiology Publications, University of Oregon.

Vargas-Tonsing, T. M., \& Bartholomew, J. B. (2004). An exploratory study of the 
effects of pre-game speeches on team efficacy beliefs. Manuscript submitted for publication.

Voight, M., \& Callaghan, J. (2001). A team building intervention program: Application and evaluation with two university soccer teams. Journal of Sport Behavior, 24(4), 420-431.

Weinberg, R., \& McDermott, M. (2002). A comparative analysis of sport and business organizations: Factors perceived critical for organization success. Journal of Applied Sport Psychology, 14, 282-298.

Wooden, J. R., \& Jamison, S. (1997). Wooden: A lifetime of observations and reflections on and off the court. Chicago, IL: Contemporary Books.

Yukelson, D. (1997). Principles of effective team building interventions in sport: A direct services approach at Penn State University. Journal of Applied Sport Psychology, 9(1), 73-96. 
Daniel Leidl Interview 112

Appendix $\mathrm{H}$

Self-Interview 


\section{Daniel Leidl \\ Primary Investigator's \\ Self-Interview}

$\underline{\text { Interview }}$

Interviewer

How did you get involved with lacrosse?

Daniel

Initially I got involved in eighth-grade. The other spring sports that were available in my town weren't really available to me. They weren't good options for me. Track and Field and baseball didn't work, and some friends played lacrosse, and it was the new thing, it was different. Not a lot of people in my town really played it, but the ones who did spoke highly of it. So, it was something I wanted to try. I liked the idea, the running element, I always liked to play soccer. My parents really frowned upon my involvement in football so the opportunity to be physical was definitely attractive because I didn't have any other outlet like that. So, I just gave it a shot.

Interviewer

Okay, what capacities have you been involved with the sport?

Daniel

Uhm, in terms of my involvement, I started obviously as a player and then I played through high school, then I played in college, and then after college I kept playing, mainly just tournaments and club lacrosse, and then it, my, the opportunities I had to continue playing continued and, uh, that also, after college led into opportunities to coach. I had always been passionate about it, and I wanted to try and coach, and I stayed involved through coaching as well as playing. So, I've coached a couple different places on the men's side. I was a head high school coach for a season. Then I got involved as an assistant with a women's program, and now I'm continuing to stay involved on the international level.

Interviewer

From your point of view, how would describe the actual culture of lacrosse?

Daniel

I think the culture of lacrosse is pretty unique in comparison to other sports. I think it's very much a tight knit community. I know that a lot of people are suggesting that it's starting to change, and I think that's inevitable as the sport grows. I don't think there's anything really condemning about that. And I remember going to camps, at Rutgers in particular, and the coaches talking about this brotherhood that existed. And, in many ways talking about it as a spiritual game, as a brotherhood, as a fraternity, as something that transcended sport, and that was pretty intriguing growing up. And, I don't think at the time I cared much about it, but looking back, no other athletic opportunities were offering that aura of inclusion. When you went to a lacrosse camp, it wasn't, it wasn't universal by any means, but when you met certain people through lacrosse you were part of something, you, an arm was around your shoulder in 
many ways. And, that sense and feeling continued when I went to college, and, and really, was heightened. And my coaches in college did a pretty amazing job, in my opinion, of really making us feel like we were looked after, like we were part of something, like people beyond our families really cared about us. And that was all an extension of the sport. And that was, as a young guy trying to figure out what's going on in your life, I, I think there's something to that. I think there was something to going to a camp and a bunch of grown men standing around and telling you how you're special just because you play a sport. And there, I remember there being talks, and there was one, Sid Jamison, was a Native American and he coached at Bucknell for a long time, I remember every year he would talk about the history of the game and what that means and the legacy that we're carrying on, and, and the impact this sport has on so many people. And again, I mean, immediately being brought into the fold. You put your helmet on, you pick up your stick, you were continually reminded that you were part of something different. And when that wasn't happening, when that, like, more historic perspective wasn't being touted there was all, always this sense of, which in some ways in, in, in, some people look down upon, but there was always this sense of lacrosse being organized skateboarding or organized surfing. Where guys, a lot of the times, playing lacrosse were guys that as a young person you looked up to. They were, they were the antiheroes. They were the James Dean type guys. They had the longer hair, sometimes they had tattoos. They didn't really fit into the main stream, but yet, a lot of times they were incredible athletes. And that was also a cool, there's a cool factor to that. To look up to these college players, even, even when I was younger, the high school players who were the cool, cool guys. And not cool in a, sometimes they had great grades, you know, sometimes they, uh, didn't, they didn't have, uh, the, the prettiest girl. They were just nice guys, some, sometimes. And there was also this antihero sense to them that was intriguing, again. So.

Interviewer

How do you think that that culture you just described has influenced you as a coach?

Daniel

I think that it's important to try and maintain this sense of legacy that was always ground into us when we were younger. And I think that that's something that's really impacted me as a coach. I think that's a lot of why I want to coach. Because it became apparent, especially through my collegiate career, that as a coach you had an opportunity to impact someone who may need to be impacted. Uhm, there is this sense that through a sport you could help someone. Through a sport you could bolster someone's spirits, or enhance someone's confidence, or bring a group of people together who really wouldn't be together, in, in, unless they rallied around that one thing. And I think that that has a lot to do with my perception of the culture of lacrosse. That there is this spiritual component. There is this sense that it transcends just an athletic event. There is this antihero climate to some of the, the big players. Uhm, and there's something unique about that. In, In many ways, you, you could get away, in my sense and I know I'm not the norm, but in my sense you could get away with walking on a lacrosse field referencing Van Gogh and Picasso, and talking about how they inspired you and you want the team to be inspired to play today. That's my, that's me. And I don't know, I don't know if you can do that in other sports. In lacrosse there's al, for me, referencing the culture, there's always been an air of uniqueness, and I like that. And I've tried to play off that in my coaching style. And I think in many ways that's what makes me an okay coach. 
Interviewer

And how does that help you motivate your team or your players?

Daniel

Well I think players get into that. I think players get into that opportunity to be unique and to define themselves through their sport with a group of other people. There's a safety in that. And it's not a mob mentality safety because that's not what I'm in to. I, I don't want to create a group of clones. I want to create a group of individuals, I want to create an environment where a group of individuals can rally around one cause. And I, I think that talking about, when, when you talk about my perception of the culture of lacrosse I think that there is a distinct opportunity to do that because you, you can rely on a lot of, there's a lot of meat to that bone. There's a lot of things you can pull from, whether it's Native American origins, or it's the lack of participants in the sport, or it's the fact that it's the fastest growing sport in the United States. There's a lot that you can pull from that get, that can, that can get people a little bit more motivated than, than maybe they were before they walked out on the field. But I, I gotta' be honest in that lacrosse, in my experience I've always worked pretty motivated people, I think. And I think that there's also, you know, that says something in and of itself. I think that the sport, and maybe there's a little bit of, like, evolution here, the, the Darwinism, sort of, component. But, I've been fortunate to coach at pretty high levels, and when you get to the higher levels people naturally want to be there. And, uh, I, I think that they buy in to a lot of what I'm selling sometimes because they want to be there. But I also think that there is something about that culture that is uniquely motivating, that reminds people that they're part of something special.

Interviewer

And how would you describe how you motivate yourself too?

Daniel

I think for me, lacrosse has been a vehicle to explore my boundaries, and, and it's been an accessible vehicle. And I think in life, those vehicles come along rarely. For some people, sadly, I don't think that they ever become readily available. And I feel very fortunate that I've had the opportunity to explore as much of myself through this sport as I have. And in, in, when you talk about motivation, I think that is, that is the motivation. To not turn my back on something that's provided me the opportunity to find as much out about myself as I have. And there's a lot of pride in that. And there's a lot of respect for that. In the sense that it's o, it's up to me to keep going, is inherently motivating. And there's also, just, this idea, and I've, I've thought about this at times, and, where I come from, you know, in terms of my background, I went to a really small Division III school, and I played there. And, some of the opportunities I have, I know firsthand from talking to guys I've played with, that they only wished they had. So I'm sure as hell not going to turn my back on the opportunities I've had when I know looking, looking at me on the sidelines, you know, waiting in the wings are a group of people who would, would give, whatever they would give for that opportunity. And I think, you know, when you talk about culture, that plays into that whole brotherhood and spiritual piece where, I, I don't want to say that, I don't owe anything to anyone, but, and I don't want to word it quite like that, but I, I care a lot about people I've met through this sport and I'm sure as hell not going to turn my back on something that I know someone I care about would give anything for. And so 
there's a lot of layers to it, but the culture certainly motivates me, and inherent within the opportunity is a degree of motivation that keeps me pushing forward.

Interviewer

And how about the team traditions. Is that something that you think influences this whole approach as well?

\section{Daniel}

I think each team is different. I think teams are like families and, and every family has its own idiosyncrasies, its own quirks. The best families, they know what they're doing and, and they're doing it often times for good reason, and that's oftentimes why they're successful. You know, and, and obviously that's the case with teams. And, I don't, I, you know, I, I think you could talk about specific traditions and specific things that go on in the context of the team that they may, it, it, it, it's, we could talk about the larger culture of lacrosse that's applicable to the smaller culture of the team. It's a unique entity. It's an environment where the individual can assert him or herself through the context of the group, and, and find success. And, and good feelings through the context of the group. And those traditions and those types of things that take place are clearly a part of that. They, they help to maintain that level of motivation. They help to remind people that they're part of something bigger than themselves. And they help to enhance that buy-in that you need from individual players for the, the group to be successful.

\section{Interviewer}

Do you think your personal, like, experiences have influenced that when you motivate and you work with your team and your players?

Daniel Yeah, I mean, I, I guess, it's all a part, it's all, it's all part of it, you know. There's no way to tease out that one thing, suggest it's not a component. I don't draw, I mean, I, I think my experiences are unique, and I think that just as every person's experiences are, and I think that they add something to the dynamic. And sometimes I draw on my experiences as a player. I think my experiences sometimes can be impactful in the sense that I really, on paper, shouldn't have been able to play with some of the people I've played with, and, and when I can remind people of that, uh, it can provide a sense of humility to the, to the environ, to the climate that I think can be valuable. Because I, at least in more recent experiences I've been able to coach some talented players and sometimes to remind them two things, one they can do whatever they set their mind to because I, I can back some of that rhetoric up, and two, don't forsake your talents because I, I, I'd be happy to tell them and anyone that I, I'm not the most talented guy but I've been able to get to wherever I've been. So, sometimes I think that can be a powerful message. And, and any coach, other people have their own messages, you know. That just happens to be some of the ones I fall back on.

Interviewer

And aside from your personal, uhm, history or your stories, do you have other stories or goals that you, you use or talk about a lot that influence this approach?

Daniel 
You know for me, I, I try to just draw on the day to day. Like, it, it, it could be a song I hear on the way to practice. It could be a movie I watched a few weeks ago. It could be someone, my friend's personal struggle, their, whatever they're going through. And I think a lot of that is, is just trying to be open to what is going on around me. And reminding people that life is tenuous, that life is what it is. And if you have two hours slated to be out with a group of friends and, and really explore yourself and be the best you can be, uh, let's take advantage of it. Because there's all this other stuff that's going on in the world that we can't ignore, and that is a reality. So if we're going, if we're going to accept that then let's try and make the most of this block of time. Where we put that all away, and really focus on, on being a team, and really focus on being as talented as we can be, and as effective and efficient we can be.

Interviewer

And what would you say motivates you as a coach?

Daniel

I think for me, I just really enjoy seeing people succeed. And I enjoy, I, I can’t even say I, I, I can't really say that it's about winning or losing or championships. I, I mean, I don't have any real championships. I, I'm different than the people I'm interviewing, you know. I, I don't have hardware or a lot of plaques. I just do it because, I think it's important that people know that there's other people in the world who want to see them succeed, and care about them, and, and want what's best for them. That motivates me a lot. It motivates me a lot to be associated with other people's success, and I don't have a clue why that is.

Interviewer

What, uhm, types of behaviors or actual practices do you find that have helped you to motivate, uhm, the players plus yourself as well?

Daniel

I think for me it's just, just doing it. The minute I walk on a field I'm pretty fired up. And if it's game day my stomach's churning and I'm, I'm ready to go. I generally have to explain to people why I'm so motivated, or why I'm so energetic or enthusiastic. I don't, I don't, usually it doesn't go the other way for me. So that's not, you know, I, I don't, I don't practice any specific behavior. It's almost what I, it's almost just part of me. I don't, you know, I mean, I don't, I don't really have any rituals or things that I do. This is what I do, and I've heard other coaches say this, and it's intriguing that, this, this is just who I am, and maybe I was lucky to find the right opportunities to exercise that.

Interviewer

Do you think that, that approach that you have, that uhm, is infectious to your players? That enthusiasm that, that you have when you walk on the field.

Daniel

Sometimes. Sometimes I think it hurts, to be honest with you because I'm so fired up that they don't understand it, and they might read that as oh, you know, he's pissed off, or oh, we better do well today because we want so badly to succeed with him, or he can't get out here so we, we'll do it for him. And that's not what I really want them to focus on. So, actually in recent years I, 
I've been trying to control some of that because I, it's hard for me to control. It's hard for me to control, quite frankly, as a player. I get amped up, I get excited. I think, I think it's, we're lucky, you know, to go out on a field to spend three hours, two hours, and be together in a controlled, presumably, relatively safe environment, and play for something that you care about, your team, to exert yourself, to be the best you can be in something. I mean, people don't think about this, but that's not, that is not an opportunity given to, I don't know what a percentage is, but most people don't have that opportunity. And when you're talking about doing it at the highest levels or, or, or high levels the, the numbers really start to thin out. And, even within that, not every team is focused on that kind of stuff. Some teams go out and they just want to win. They don't, they don't care, they don't think about the other components to this. They don't think about the opportunity to exert yourself as a human being and blah, blah, blah, blah, blah, you know, let's come together as a team. So, really I, I don't know how many groups of people go out on a Saturday or a Sunday and, and talk about this kind of stuff, and, and explore it for a couple hours and then get, get back together on Monday to talk about it, and, and to keep practicing for the next time they do it. And when you're, when you're in that, it's, for me, pretty inspiring, pretty cool.

Interviewer

How would you describe your goals as a coach?

Daniel

I'm in a, I'm in a different place than the coaches I'm talking to. You know, I don't, I don't have goals as a coach. To keep, to coach another game? You know, like, I don't even know what to say. I'm not even a coach. I, I don't, I, I feel sometimes really like I'm on the Island of uh Misfit Toys. You know, I don't really have the outlet that a lot of these people have. I'm lucky to be asked to coach for two weeks a year with an international team, and that's a blessing, and I'm going to go out there and do it the best I, I freaking can. And, and that's all I know. And, I think if I have any goal it's just to approach whatever situation I'm involved in as best as I can. And that zaps me of a lot of energy, and it makes my roommate really tired too because I talk about it, and I obsess about it, and I really try and give it everything I can. I, I don't know. I don't really have any other goals. I would like to continue to coach. Like I said, I'd like to coach, continue to coach. I'd like to find some level of success that is tangible. I mean, that would be a great, that's more of a dream, you know. I would love to be able to point to my career and say, hey this is what I did, look on the wall, look in my trophy case because that's cool and it's, it's there, it's substantive, but that's not something that drives me.

Interviewer

Are there, now with your goals being what they are, what you just described, are there specific things that you do, behaviors or anything you do just to kind of make those, that short experience that you do have, when you have them, work?

Daniel

Yeah, I mean I, I try hard. You know, I, I, I talk to the players. I, I remind them that my goal is not, uh, a, a medal or a ring. I tell them that I'm, I, I want to see them succeed. You know when you talk about goals, just to backtrack a little bit, I mean one of my goals, I would love, I would love nothing more than for a player I coached to call me up in 25 years and say, hey do you want 
to go out to dinner, I haven't talked to you in a while. And just know that those relationships are still open. I get a, I, I enjoy that. And, and I enjoy feeling like I may have impacted the way my coaches impacted because I know how critical their involvement was to my own development. And if I could afford someone else that opportunity, I'm going to take it. And I think that if I could walk out on a field in 50 years with the Irish team that's going to compete this summer or that competed last summer, and, and, and they can do a little announcement, this was the first Irish team and I'm there. Uh, and we can all go out to dinner later and joke around about what, what happened, and, and all that kind of stuff, that's a, that would be a good goal for me. And I think that's, in terms of behavior, that's the kind of stuff that I focus on, and that's the kind of stuff that I try and let other people know that I care about. And I believe that when you do that, and you do, and obviously I'm no talking x's and o's here, you gotta' focus on the strategy, and you gotta' practice, and you, you have to be hard on people sometimes, and you gotta' call people out, and you gotta' have meetings that no one else really wants to have because you have to be willing to step up and tell that one person that they're, they're really not working hard even though you like that kid a lot, and you don't want to hurt them, and you don't wan to damage the relationship, you gotta' figure out a way to do it so that they're not going to look at you any less but at the same time, they're gonna', they're gonna' work harder or they're gonna' do what you're, what you feel like they need to do. So there's a lot of other stuff that goes into it, you know. But I just try to work under that principle that before anything else, I, I'm trying to maintain human relationships. And, and I want those people to know that I care about them by virtue of the fact that they're on my team. And there's nothing, that's how it, it starts and stops there. You're on my team, I care about you. If I, if I was involved with selecting you to be on this team it was because I saw something in you, and I want that something to shine. 
Appendix I

A Review of the Qualitative Process 


\section{Initial Code Sheet \\ Outline}

1. Theme - Initial Motives to be Involved

a. As a Player

i. Mentors

1. Peers

2. Coaches

ii. Escape/Necessity

iii. Love at First Site

iv. Early Success/Talent

v. Early Adversity - Effort - Persistence

b. As a Coach

i. Destiny/Luck/Opportunity - How I got here

ii. The Initial Hook

2. Theme - It's Larger than One Team - Cultural Motives

a. Changing Motives

b. It's Unique

c. Historical Importance - Motivation to Continue Legacy

d. Social/Inclusive

e. Great Schools \& People

While the excerpts that related to the larger culture of lacrosse were truly fascinating they did not offer insights that related to the research questions driving this article.

3. Theme - It's Larger than the Individual - Team Motives

a. Non-Lacrosse Efforts to Motivate

i. Off-Field Activities

ii. Mottos

iii. Unique Efforts

iv. Artifacts

v. Big Picture Focus/Beyond x's \& o's

vi. Getting Them to Think - Developing a Mindset

vii. Stories - History

viii. Us vs Them - Bunker Down

b. Lacrosse Related Efforts to Motivate

i. Pushing \& Prodding/Accountability - Positive \& Negative

ii. The Culture of Edging

iii. The Desire to Sustain Success

iv. FUN - Enjoyable

v. Inter-Team Competition/Practice/TEAM

vi. Intra-Team Competition/Games

vii. Empower the Players/Investment

c. Team Dynamics/Camaraderie

i. Coach to Coach Relationships

ii. Know the Players

iii. Inter-Team Relationships/Unity

In conferring with the research assistants, it became apparent that a number of these categories were actually representing larger values that the coaches were expressing throughout varying sections of the interviews. 
iv. Exterior Influences

v. Leadership

4. Theme-Commitment to Success

a. Coach's Commitment

i. Recruiting

ii. I Work Hard

iii. Individual Growth

iv. Individual Responsibility - Fear or Otherwise

5. Theme - Why I Coach

a. Current Motives

i. Identifying with the Job

ii. Identifying with the Sport

iii. I want to see them Excel

1. On Field

2. Off Field

iv. New Possibilities

v. Bringing the Group Together

vi. Legacy

6. Theme - When All Else Fails

a. Current Examples

b. The Problem

c. The Solution

i. History

ii. Communication

iii. Look in the Mirror

iv. Positive

d. The Outcome

Many of the examples that were presented in this category were eventually included under the categories related to more general motivational methods (e.g., Hard Work, Camaraderie, etc.). 


\title{
Initial Code Sheet \\ Description
}

- 62 Pages

- Comprehensive thematic representation of all the data

- Reviewed by research assistants following their reading of all transcriptions

- Many themes eventually deemed irrelevant to research article (e.g., When all else fails, Initial motives to be involved, etc.) and subsequently separated

To follow are some examples:

\section{Theme - Initial Motives to be Involved Category - As a Player \\ Mentors \\ $\underline{\text { Peers }}$}

Jim Berkman

"I had played a little bit of lacrosse as far as playing catch and that kind of stuff, and one of, one of my friends, like in seventh grade, he was little bit older than me and lived in our neighborhood, he gave me, like, a wooden stick. You know, and for weeks I'd go down to his house and we'd play catch, and I had one of those wooden, wooden sticks.”

“And uhm, me and my buddy Pete Powell, who is a big lacrosse guy up in Watertown, says, man you've got to play lacrosse, you gotta' play lacrosse. So I'm sitting there in the lobby, like, you know, a day before practice is getting ready to start and he convinces me, go play lacrosse.”

Julie Meyers

"Same teammates, same uniform, same numbers, I mean, like literally it was, we just played hockey in the fall, and then we doubled over and played lacrosse in the spring.”

\author{
Coaches \\ Julie Meyers \\ "So, you know, I kind of stumbled on to lacrosse, but the hockey and lacrosse kind of connected \\ really neatly where it was the same coaches. Even in high school for the most part, and then \\ obviously in college it was the same set of, it was the same coaching staff that was hockey and \\ lacrosse." \\ “I was gonna' go to Penn State, and the night before I signed with Penn State Jean calls for the \\ first time. I had never met her, I had never visited. She’s like do you want to go to Virginia? \\ I'm like, yeah. So literally I hung up the phone as a senior in high school and I said mom, I'm \\ gonna' go to Virginia." \\ Chris Paradis \\ "I started playing field hockey, and that kind of, in turn, led to me playing lacrosse because it \\ was the same coach." \\ "I’ve had important mentors in my lacrosse life.”
}


Secondary Code Sheet

Outline

1. Introducing the Coaches - I am Lacrosse

Categories

1. The Initial Hook

2. Identifying with the Sport

3. Identifying with the Job

2. Committing to the Sport - The Values of a Champion

Data regarding the coaches' initial introduction to lacrosse and motives to originally begin coaching was deemed irrelevant to the larger focus of this article.

Categories

1. Empowerment

2. Leadership

3. Camaraderie

4. Hard Work

a. Bringing the Group Together

b. Inter-Team Relationships/Unity

5. Growth

6. Excellence

a. On Field

b. Off Field

7. Individual Responsibility - Fear or Otherwise

8. FUN-Enjoyable

3. Passing the Torch - Actively Motivating Success in Others

Categories

1. Non-Lacrosse Efforts to Motivate

2. Off-Field Activities

3. Mottos

4. Unique Efforts

5. Artifacts

6. Getting Them to Think-Developing a Mindset

7. Stories - History

8. Pushing \& Prodding/Accountability - Positive \& Negative

9. The Culture of Edging

10. The Desire to Sustain Success

11. Inter-Team Competition/Practice/TEAM

12. Intra-Team Competition/Games

4. What we're Striving For - Big Picture Vision

Categories

1. Legacy

2. Big Picture Focus/Beyond x's \& o's
In this example, the first 5 categories under Passing the Torch were eventually condensed into one (i.e., Offfield Efforts) or removed due too few excerpts. 


\section{Secondary Code Sheet}

Description

- 40 pages

- Condensed thematic representation of relevant data

- Developed with the assistance of research assistants

- Focused on more relevant material

- Developing workable model and interconnected themes

To follow are some examples:

\section{Theme}

2. Committing to the Sport - The Values of a Champion

\section{Categories}

\section{Empowerment}

Missy Foote

"And it's just a conversation. And those are the, the sort of failsafe mechanisms for me because what I know is they got it, they, they played the game. In some ways they got it more than I do. They, they know what they need to do.”

"I'm at the point of, you know, the top of that map, but everyone else is pretty close to me. My captains are kind of right next to me.”

\section{Julie Meyers}

"we empower. Like we, everybody has a chance to have their say or, or to direct the ship, or to, to chime in. You know, nobody, nobody feels like a jerk for saying something.”

"But we empower everybody enough with umh, with being a maturing young adult and we roll with their mistakes early, and we just expect as they get older and more mature in the process that their leadership starts to come out because they've been empowered at a younger age.”

\section{Hard Work}

\section{Jim Berkman}

"I mean, I was here at ten of seven this morning. You know, I don't think there's too many other Division III coaches that are in their office ten of seven in the in the summer. You know, Coach Knight just came in, but if you go through this office you're probably not going to see another coach in it today, too."

“But, you know, it’s constant, you got to stay focused, you got to keep working hard.”

Missy Foote

“And then, that's my other challenge, then it's me, A, designing a drill to help them get there. Sometimes it's a simple as, yeah, we couldn't transition the ball because we were getting pressured, it's something that simple. So I've got to come down, and come up with a life like drill, a game like drill, that's going to help them have confidence so they can do it the next time. And that's a, that's a huge challenge. I love that challenge.” 


\section{Final Code Sheet \\ Outline}

1. Coach's Commitment: I am Lacrosse

2. Values
a. Empowerment
b. Camaraderie
c. Hard Work
d. Growth
e. Excellence
f. Responsibility
g. Fun

3. Motivating Tools
a. Off-field Efforts
b. Stories
c. Reinforcement
d. Accountability
e. The Culture of Edging
f. Competition
g. Sustaining success

4. Big Picture

\section{Final Code Sheet \\ Description}

- This Final Outline represents the excerpts and model that appears in the final article

- Similar codes (e.g., the first five categories of Passing the Torch) were grouped together

- Codes that were not relevant to the research questions driving this particular article were removed

- Codes that only represented one or two coaches were eliminated

- Categories and Themes were finalized

Examples and further descriptions are best found throughout this article:

"Motivation in Sport: Bridging Historical and Contemporary Theory Through a Qualitative Approach" 